\title{
Motivation, Human Capital Investment and Compensation in an Agency Problem
}

\author{
Anthony M. Marino ${ }^{1}$ \\ ${ }^{1}$ Marshall School of Business, University of Southern California, Los Angeles, CA, USA \\ Correspondence: Anthony M. Marino, Marshall School of Business, University of Southern California, Los Angeles, \\ CA 90089-1422, USA.
}

Received: July 6, 2019

Accepted: July 29, 2019

Online Published: July 31, 2019

doi:10.5430/jms.v10n4p37

URL: https://doi.org/10.5430/jms.v10n4p37

\begin{abstract}
This paper considers a firm's optimal investment in training and motivation measures in a hidden action agency problem. We study how these strategies interact with each other and the contract in order to create value for the firm. Productivity enhancing training can be firm specific or non-firm specific and firm specific motivation can enhance utility or reduce effort cost. Whether these measures are complements or independents depends on the firm specificity of human capital and whether the participation constraint is binding. We characterize how a tighter labor market affects marginal profitabilities and examine the relative benefits of motivation measures which enhance utility versus those which decrease effort cost.
\end{abstract}

Keywords: human capital, motivation, agency

JEL Code: L20, L21, L22, L23

\section{Introduction}

Firms and organizations invest resources in educating and motivating their employees. In many cases this aspect of organizational strategy must be implemented in the presence of an agency problem. This paper will study the optimal selection of investments in training and motivation in conjunction with the optimal choice of a monetary compensation contract. We will investigate how these two non-monetary instruments interact, how each contributes to value for the firm, and how these measures interface with the optimal contract in the context of a hidden action agency problem.

United States corporate expenditure on direct learning averaged \$252 (Note 1) per employee in 2015, and corporate education grew to over $15 \%$ in 2013 to over 70 billion in terms of total dollars spent (Note 2). Worldwide, in this same period over 130 billion dollars were allocated to corporate training (Note 3). For many firms such as Google, Apple, Motorola, and Hewlett-Packard, in kind benefit expenditures meant to motivate employees are even greater than the amount spent per employee on direct learning.

Corporations devote serious resources to value enhancing training and motivation programs in addition to their monetary pay packages. It is of economic interest to examine how these three different strategies optimally interact in the context of an agency model. This paper will present the first rigorous analysis of the interaction of these three important strategies for the case where there is a moral hazard problem. As a first cut at this interesting issue, we employ a fairly specific model of complementarity among the wage, motivation and education measures.

Our model will analyze educational investment which has the goal of making the agent's expected productivity increase. The level of productivity is complementary with the agent's effort in the cash flow technology. We will consider education to enhance productivity that is either firm specific or general. In the former case, an increase in the agent's productivity does not lead to an increase in that agent's outside option, whereas in the latter case it does. Investment measures which motivate the agent are modeled either as enhancing the agent's expected utility of the wage or as decreasing the agent's expected effort cost. Motivation measures are regarded as being firm specific, so that such measures do not increase the agent's outside option. We introduce an interesting trade off in that productivity enhancing measures have a more direct positive impact on cash flow than motivation measures. However, the former can raise the outside option, while the latter do not do so. In fact, motivational investment is used in some real world organizations to tie the agent to the firm through personal services and relationships which 
would be hard to duplicate outside the firm.

We begin by considering motivation measures which enhance the agent's gross and marginal utility of the wage and later consider effort cost reducing measures (Note 4). Initially, we make the assumption that, pre-contract, the firm is endowed with exogenous levels of the agent's productivity and motivation. Given these levels, the firm writes a compensation contract for the agent in context of a simple two outcome hidden action agency problem with a general effort cost function. We use this model as an exploratory device to see how, through comparative static changes, the two measures interact (Are they complements or independents?) and how they might relatively contribute to revenue at the firm's second best contract.

The results depend on whether the agent's participation constraint is binding or non-binding and on the firm specificity of human capital investment. If the participation constraint is non-binding, then the two measures are strategic complements (the marginal profitability of training increases in motivation). In this case, firms with high motivation and low productivity will benefit more on the margin from education measures than from motivation measures. Effort is increasing in productivity and motivation, whereas the contingent payment to the agent can be uniformly increasing constant or decreasing in motivation and productivity depending on the form of effort cost. That is, a substitute, complement or independent relationship is possible between compensation and these strategies.

If the participation constraint is binding and human capital investment is general, then the two strategies are again complements. In this case, the marginal profitability of training is increasing or constant in motivation as the outside option is increasing or constant in the productivity of the agent. Thus, general training increases productivity, increases the outside option and makes the measures complements, whereas specific training keeps the outside option constant and makes the measures independents. The agent's contingent payment is decreasing in motivation (substitute relationship), but can be increasing or decreasing in the agent's productivity in the non-firm specific case (complement or substitute relationship). In the firm specific case, the contingent payment decreases in the agent's productivity (substitute relationship). The agent's effort is only a function of his/her outside option and, thus, increases in the outside option only if productivity rises and training is general. Regardless of firm specificity, if the participation constraint is binding, the marginal benefit of education relative to motivation is increasing in firm size and the level of motivation.

Next, we introduce a more specific stochastic pre-contract investment model where the firm can invest resources to increase the probabilities that an agent would have a high productivity level and/or a high motivation level. In this model, cash flow effort cost and the costs of both investment measures are assumed to be of the power function form. We adopt this model in order to obtain a closed form solution for cash flow effort and the incentive contract. We characterize the second best equilibrium, work out the complete comparative statics of this equilibrium in each of the non-binding and binding cases, and we discuss how the monetary contract changes for each of these cases.

If the participation constraint is binding and human capital is general, then increases in expected productivity through educational investment will increase the expected outside option for the employee. The greater is the increase in the outside option for a given increase in the agent's productivity, the tighter or the more competitive is the labor market. For this case, we parameterize the increase in the outside option and show that a tighter labor market increases the marginal profitability of motivation measures and decreases that of education measures. However, the effects of increased tightness on the equilibrium investments in these measures can go in either direction. We show that the results are clearly dependent on the firm controlling both measures and we show that interactive effects can generate counter intuitive changes.

Finally, we study the alternative assumption that motivation decreases expected effort costs as opposed to enhancing utility. In the deterministic/exogenous version of the model, we make an interesting comparison between effort cost reduction motivation measures and those which enhance utility, by comparing the effect of each on the firm's revenue. We show that small firms can generate greater revenue increases by investing in measures which enhance utility, whereas larger firms generate greater revenue by implementing measures which decrease effort cost. For the stochastic model with power function costs, the above results do not change, if the participation constraint is non-binding. If the participation constraint is binding then the measures are strategic complements regardless of the firm specificity of human capital. That is, the independence results with utility enhancing motivation are overturned. The results on a tighter labor market are robust to the cost reduction case.

Section 2 discusses related literature. Section 3 presents the basic model, and Section 4 outlines the stochastic investment model for training and motivational measures. Section 5 presents the results on tightness of the labor market and Section 6 provides an analysis of the case where motivation lowers effort cost. Section 7 concludes. 


\section{Related Literature}

This paper is connected to the strand of the agency literature in which the principal controls aspects of the agency relationship in addition to the monetary contract. (Holmstrom and Milgrom, 1991) consider optimal task assignment along with optimal compensation. (Besanko and Sibley, 1991) analyze transfer pricing and compensation with hidden action and information. The papers of Hirshleifer and Suh, 1992) and (Sung, 1995) examine a hidden action contracting problem where the principal also controls project choice. (Harris and Raviv, 1996) characterize optimal capital assignment in the context of a hidden information contracting problem. (Garcia, 2014) and (Bernardo et al., 2001) also examine capital allocation and compensation in the presence of hidden action and information. (Feltham and Xie, 1994) study a hidden action problem where the principal sets the agent's performance measure and selects the optimal contract.

The papers by (Marino and Zabojnik, 2008), (Marino and Ozbas, 2014), (Marino, 2015), and (Kvaloy and Schottner, 2015) examine hidden action agency problems where the principal sets the contract along with a secondary non-monetary control variable. (Marino and Zabojnik, 2008) introduce a work related perk into the contracting problem, (Marino and Ozbas, 2014) allow the principal to release information which determines the agent's status in conjunction with the contract, and (Marino, 2015) blends the contract with a selection of safety in the workplace. (Kvaloy and Schottner, 2015) introduce costly motivation into a hidden action agency problem using a general cost of effort function. In this paper, motivation reduces effort cost, and the focus is to analyze the optimal combination of motivational effort and monetary compensation. Our paper differs from this study because it considers the interaction of training, motivation and compensation in the same model, with main focus on the interaction between training and utility enhancing motivation. We also differ in that both motivation which enhances utility as well as motivation which reduces effort cost are considered and compared, and we study the effects of firm specificity versus non-firm specificity of training measures. While our scope is broader, our cost structure is more specific due to the added complexity.

Relative to the existing literature, our paper is the first to consider specific and general education strategies as well as motivation strategies in the context of a moral hazard problem. While our model is fairly specific, it allows a rigorous initial examination of this very interesting problem.

\section{The Basic Model: Hidden Action With Motivation and Training Measures}

Consider a principal-agent situation where the agent exerts unobservable effort to produce cash flow for a principal. Generally, we write the agent's utility as the difference between the gross utility of the wage and the agent's cost of effort. A principal can motivate and train (so as increase productivity) the agent in various costly ways.

To characterize motivation, we follow much of the behavioral literature and assume that more motivation has the effect of raising the gross utility of the agent or lowering the agent's effort cost. Let $w$ denote the wage paid to the agent, let $\gamma$ denote measures controlled by the principal to reduce the agent's effort cost, let $\mathrm{b}$ denote measures controlled by the principal to increase the agent's gross utility of the wage, and let $\mathrm{x}$ denote effort which is not observable by the principal. If the agent is risk neutral, then these relationships can be captured in the utility function $u=u(w, b, \gamma)=b w-c(x, \gamma)$, where $u_{b}, u_{b w}>0$ and $c_{\gamma}, c_{\gamma x}<0$ (Note 5).

The assumption that $u_{b}, u_{b w}>0$ says that motivation enhances utility and that the marginal utility of wealth increases in motivation. This assumption is motivated by (Maslow's, 1943) hierarchy of needs. Consistent with Maslow's theory that self esteem, status, and self-actualization motives are high-level psychological needs that come only after basic physiological necessities are met and that motivation directly feeds these needs, the positive interaction between motivation and wealth implies that more wealthy agents care more about the results of motivation. While advances from related fields continue to refine thinking in psychology in significant ways, the key elements of Maslow's hierarchical approach to understanding human motivation remain central (Kenrick et al., 2010).

We will show that it definitely matters in terms of results whether motivation affects gross utility or effort cost. Economists are generally more inclined to think about motivation as being implemented through perks which reduce the opportunity cost of effort. However, we will argue that it is also common for firms to expend resources on attempting to make their employees generally happier about working for their company through the use of measures which are not primarily effort cost reducing. There is, of course, a gray area when drawing a distinction between these two strategies, with some measures tilting towards the gross utility rationale and some towards the effort cost rationale. We will give specific examples of each case with an emphasis on utility enhancement, since this requires more explanation. 
Measures which would enhance utility as a result of being part of the organization might include creating an atmosphere of respect and dignity in interactions, where agents are complemented, recognized and supported for tasks well done and where the principal takes time to learn the interests and needs of the agent and keep lines of communication open. Measures such as the holding of off site social events so as to create team spirit and a sense of community and the provision of clear information on the goals of the organization, so as to promote a pro-corporate culture fall into this category. Apart from these psychological measures, the firm can enhance utility by providing a pleasant physical work environment such as a nice office with a view, access to a gym, and provision of leisure activities such as making game rooms available to employees. There are many real world examples where gross utility enhancement seems to be the primary goal of the firm or organization. Penguin Random House offers employees free books and e-books from over 100 titles. Workers can join book clubs with co-workers to discuss plots. Ben and Jerry's offers three pints of its ice cream to employees each day to take home and share. Facebook focuses on the family by offering four months of parental leave and reimbursement for adoption fees. The Goddard School, Jennifer Adams Worldwide, Airbnb and Zimba give their employees paid time off or flexible hours to do volunteer work. Airbnb also pays for employee donations to charities each month and gives quarterly credits towards free lodging. The Goddard School, Jennifer Adams Worldwide and Zimba give their employees paid time off or flexible hours to do volunteer work. Quicken loans gives out free events tickets and transportation to events. Finally, Epic Systems gives freedom and money to travel for an employee and one guest. These grants are given every five years (Note 6). In each of these cases, it is reasonable to assume that the total and marginal utility the wage would be positively related to the provision of such motivation measures. Such perks primarily motivate by raising the gross utility of the wage, at a given effort cost.

Measures which would decrease marginal and total effort cost would include all perks which decrease the opportunity cost of working. Examples include good day care (for children as well as pets (Note 7)), laundry services, food and snack service, or other personal services including onsite medical services, hair cutting service and transportation to and from work. These perks primarily motivate the agent by freeing time up away from personal duties so that the opportunity cost of work effort is less, and, at a given gross utility, gross utility minus effort cost becomes greater.

If we use a multiplicative specification for $\gamma$, then the agent's utility takes the form $b w-c(x)$ or the form $w-\gamma^{-1} c(x)$. For the most part, we will adopt the utility enhancement form for studying motivation and later discuss the implications of using the effort cost reducing form. The variable $b$ will represent the agent's motivation level. We appropriately scale $b$ such that $b>1$, so that $b$ could be interpreted as a utility enhancer or the power of motivation.

Cash flow in the firm is given by $y \in\{0, a y\}$, ay $>0$, where $a \geqq 1$ is a productivity parameter which augments the high cash flow. The probability of the high cash flow is given by Prob (ay) $=x$. We assume that $x \in[0,1)$. We can interpret the productivity variable $a$ analogous to the way that we interpret the variable $b$, in that a measures an enhancement to the high cash flow made possible by increased productivity of effort. The parameter $y$ is the monetary reward for success, and, to the extent that larger firms reap greater success, we will think of $y$ as a "firm size" measure.

We assume that the agent's level of motivation $b$ is a firm specific entity and, as such, increases in $b$ do not affect the agent's outside option. On the other hand, the level of productivity $a$ may not be entirely firm specific, so that increases in $a$ could affect the agent's outside option in a positive way. Let the function $u(a)$ denote the agent's outside option, where we assume that $u^{\prime}(a) \geqq 0$. If $u^{\prime}(a)=0$, then increments to human capital will be thought of as firm specific, whereas if $u^{\prime}(a)>0$, then the human capital investment is general (Note 8).

In this section, we treat $a$ and $b$ as exogenous public information and conduct comparative statics on these levels in an effort to see how they impact profit and how they interact (Note 9). In the next section, we will allow the principal to invest costly resources in an effort to make $a$ and $b$ larger in a stochastic sense.

The principal's contract is given by a non-contingent salary $\alpha$ and a share $\beta$ of expected cash flow of the firm. The agent chooses effort according to

$$
\max _{x} b(\alpha+\beta a x y)-c(x)
$$

From this problem, the first order condition $b \beta a y-c^{\prime}(x)=0$ gives us a solution for $\mathrm{x}$

$$
\left.x=c^{\prime-1}(b \beta a y) \equiv x(b \beta a y)\right)
$$

We assume that the effort cost function satisfies

A.1 $c(0)=c^{\prime}(0)=0, c^{\prime}, c^{\prime \prime}>0$ for $x>0$, and $c^{\prime \prime \prime} \geqq 0$ 
We assume that marginal and total cost of effort are zero, for zero effort, that effort cost is strictly convex, and that marginal effort cost is regular convex. The inverse marginal cost function $x(\cdot)$ then satisfies

$$
x(0)=0 \text {, and } x^{\prime}>0, x^{\prime \prime} \leqq 0 \text { for }(b \beta a y)>0
$$

Next, consider the principal's problem. The principal is risk neutral and has the task of choosing $x, \alpha$ and $\beta$ so as to maximize expected profit subject to incentive compatibility, subject to limited liability (limited liability in the sense that the agent only receives non-negative payments), $\alpha, \beta \geqq 0$, and subject to the agent's participation constraint,

$$
(b(\alpha+\beta a x y)-c(x)-u(a) \geqq 0
$$

The principal's Lagrangian function is

$$
L=-\alpha+(1-\beta) y a x+\lambda[b(\alpha+\beta a x y)-c(x)-u(a)]+\mu\left[\beta b a y-c^{\prime}(x)\right]+\mu_{\alpha} \alpha+\mu_{\beta} \beta+\mu_{x} x
$$

The variables $\mu_{i}$ denote the multipliers for the nonnegativity constraints on the choice variables, $\mu$ is the multiplier for the incentive compatibility constraint, and $\lambda$ is the multiplier for the participation constraint. The first order conditions for $\alpha$ are

$$
-1+\lambda b+\mu_{\alpha}=0, \mu_{\alpha} \alpha=0, \alpha, \mu_{\alpha} \geqq 0
$$

The first order conditions for the participation constraint tell us that

$$
\lambda[b(\alpha+\beta a x y)-c(x)-u(a)]=0, \lambda,[b(\alpha+\beta a x y)-c(x)-u(a)] \geqq 0
$$

The incentive compatibility constraint and the first order condition for $x$ are

$$
\begin{gathered}
\beta b a y-c^{\prime}(x)=0 \\
\text { and }(1-\beta) y a+\lambda\left[\beta b a y-c^{\prime}(x)\right]-\mu c^{\prime \prime}(x)+\mu_{x}=(1-\beta) y a-\mu c^{\prime \prime}(x)+\mu_{x}=0
\end{gathered}
$$

The first order conditions for $\beta$ are

$$
-y a x+\mu b a y+\lambda b a x y+\mu_{\beta}=0, \beta, \mu_{\beta} \geqq 0, \beta \mu_{\beta}=0
$$

There are two solutions of interest. Namely, the solution in which the participation constraint is non-binding and that in which it is binding. Before considering these two cases, we prove (All proofs are provided in the Appendix.)

Lemma 1: In equilibrium, we have that the optimal $\alpha=0$. Further, if $u(a)=0$, then the participation constraint is non-binding.

Lemma 1 says that if the outside option is very low, then the participation constraint is non-binding. In the non-binding case, the principal and the agent share a surplus above the outside option. Define the surplus function

$$
S(x) \equiv x c^{\prime}(x)-c(x)
$$

If the constraint is non-binding,

$$
S(x)=b \beta a x y-c(x)>u(a)
$$

We have that $S(x)>0$, by $c(0)=0$ and $c^{\prime}, c^{\prime \prime}>0$ (Note 10). If $u(a)=0$, then the participation constraint is always non-binding. Due to limited liability, regardless of whether the participation constraint is binding or not, the principal does not employ a positive fixed wage as part of the optimal contract.

\subsection{The Participation Constraint Is Non-binding}

Consider the case where the participation constraint is non-binding or, alternatively, the case where $u(a)=0$. The do-nothing solution where all choice variables are zero is uninteresting, so that it is ignored. Consider (7) and (8). We have that the multiplier on the participation constraint is zero, $\lambda=0$, and that $\mathrm{x}, \beta>0$ which implies that $\mu_{x}, \mu_{\beta}=0$. Equation (8) implies $\mu=x / b$. Substituting into (7) and solving for $x$, we have

$$
x=(1-\beta) b y a / c^{\prime \prime}
$$

The incentive compatibility constraint implies

$$
\beta=c^{\prime}(x) / b a y
$$

Substitute (10) into (9) and solve for bay

$$
\text { bay }=c^{\prime \prime} x+c^{\prime}
$$

Define the function

$$
G(x) \equiv c^{\prime \prime} x+c^{\prime}
$$

Note that $G^{\prime}=x c^{\prime \prime \prime}+2 c^{\prime \prime}>0$ under A.1, so that $G$ has an inverse. Whence, the solutions for $x$ and $\beta$ with a 
non-binding participation constraint, from (11) and (10), are (Note 11)

$$
\begin{gathered}
x^{N}=G^{-1}(\text { bay }) \\
\text { and } \beta^{N}=c^{\prime}\left(G^{-1}(\text { bay })\right) / b a y
\end{gathered}
$$

It turns out that the optimal incentive share has an upper bound of $1 / 2$ in the case of a non-binding participation constraint. We have

Lemma 2: Let A.1 hold and let the participation constraint be non-binding, then $\beta \leqq 1 / 2$.

The principal optimally does not give up a majority of the cash flow to the agent in an equilibrium where the participation constraint is non-binding. In this case, the agent and the principal share a surplus, but the principal keeps no less than a $50 \%$ share.

The agent's effort is increasing in the level of motivation, the level of productivity and the firm size. Using (12), this is true from the fact that $G^{-1 /}>0$.

The optimal incentive share changes in a uniform qualitative fashion with changes in the productivity parameter a, the motivation parameter $b$, and the firm size parameter $y$. Employing (13),

$$
\operatorname{sign} \partial \beta^{N} / \partial i=\operatorname{sign}\left(\left(\left(c^{\prime \prime}\right) /\left(c^{\prime \prime \prime} G^{-1}(b a y)+2 c^{\prime \prime}\right)\right) b a y-c^{\prime}\right) \text {, for } i=a, b, y
$$

Depending on the form of the effort cost function, the sign of $\partial \beta^{N} / \partial i$ is the same for $i=a, b, y$. Without more specific information on the effort cost, this derivative cannot be signed. For example, if c takes the form $e^{x}-(x+1)$, then $\beta^{N}$ is decreasing in $i=a, b, y$, whereas if $c=x^{v}$, then $\beta^{N}=\frac{1}{v}$, and it is a constant function.

We now want to examine the comparative statics of the parameters a and b at an (optimal contract) equilibrium. Using equations (12) and (13), the firm's equilibrium profit with a non-binding participation constraint is

$$
\pi^{N}=a y G^{-1}(\text { bay })-c^{\prime}\left(G^{-1}(\text { bay })\right) G^{-1}(\text { bay }) / b
$$

The marginal profit of a is

$$
\begin{aligned}
\pi_{a}^{N} & =\left(\left(\left(b y-c^{\prime \prime} G^{-1 \prime} b y\right) / b\right)\right) G^{-1}+\left(\left(b a y-c^{\prime}\right) / b\right) G^{-1} b y \\
& =y G^{-1}-c^{\prime \prime} G^{-11} y G^{-1}+\left(b a y-c^{\prime}\right) y G^{-1 \prime}
\end{aligned}
$$

From (11), $\left(\right.$ bay-c $\left.c^{\prime}\right)=x c^{\prime \prime}$ and, from (12), $x=G^{-1}$. Substituting,

$$
\pi_{a}^{N}=y G^{-1}(\text { bay })
$$

The marginal profit of $b$ is

$$
\pi_{b}^{N}=G^{-1}\left(\left(\left(c^{\prime}\right) /\left(b^{2}\right)\right)-\left(\left(c^{\prime \prime} G^{-1 \prime} a y\right) / b\right)\right)+\left(\left(b a y-c^{\prime}\right) / b\right) G^{-1 \prime} a y
$$

Substituting $\left(\right.$ bay $\left.-c^{\prime}\right)=x c^{\prime \prime}$, from $(11)$,

$$
\pi_{b}^{N}=c^{\prime}\left(G^{-1}(\text { bay })\right) G^{-1}(\text { bay }) / b^{2}
$$

It is clear that productivity and motivation are complementary in equilibrium in the non-binding case. We have that

$$
\pi_{a b}^{N}=y G^{-1 \prime}(\text { bay }) a y>0
$$

Next, let us explore the difference $\pi_{a}^{N}-\pi_{b}^{N}$. Because we have ignored the marginal costs of increasing $a$ or $b$, profit and revenue variations are equivalent (Note 12). From (15) and (16),

$$
\pi_{a}^{N}-\pi_{b}^{N}=y G^{-1}(\text { bay })-\left(\left(c^{\prime}\left(G^{-1}(\text { bay })\right) G^{-1}(\text { bay })\right) /\left(b^{2}\right)\right)
$$

We can show

Proposition 1: Let the participation constraint be non-binding. If $b \geqq a$, then $\pi_{a}^{N}-\pi_{b}^{N}$ is increasing in $y$ and $b$. $\pi_{a}^{N}-\pi_{b}^{N}$ is increasing or constant or decreasing in a as $b \underset{<}{<} a$.

As the level of employee productivity increases, the relative importance of training in raising revenue increases, if power of motivation is greater than that of productivity, and, conversely, it decreases if the power of training is greater than that of motivation. Moreover, in situations where the power of motivation is great relative to the power of productivity, greater motivation and larger firm size improve the relative importance of training in raising revenue. Empirically, we predict that the marginal revenue differential between training and motivation is increasing in the level of productivity, the size of the firm and the level of motivation, when the employees are highly motivated. This effect may be behind expansions in training at large firms such as Google, where employees seem to be highly 
motivated.

\subsection{The Participation Constraint Is Binding}

Next, consider the firm's problem where the participation constraint is binding. Given $\alpha=0$, the incentive compatibility constraint (6) and the binding participation constraint imply that $S(x)=u(a)$. Given that $\mathrm{S}^{\prime}(x)=c^{\prime \prime} x+$ $2 c^{\prime}>0, S$ has an inverse, and the solution for effort at a binding solution is

$$
x^{B}=S^{-1}(u(a))
$$

The surplus function $S(x)=c^{\prime}(x) x-c(x)$ is increasing in $x$, by $S^{\prime}=c^{\prime \prime} x>0$, for $x>0$. Moreover, we have that $S(0)=$ 0 and $x \in[0,1)$. Thus, for the participation constraint to be met, we require the necessary condition

A. $2 S(1)>u(a)$

If A.1 and A.2 are true, then, because $S(0)=0$ and $S^{\prime}>0$, there is an $x$ which creates a binding participation constraint. Substitute (17) into the incentive compatibility constraint (6), and we have

$$
\beta^{B}=\left(c^{\prime}\left(S^{-1}(u(a))\right) /(\text { bay })\right.
$$

The binding solution, $\left(x^{B}, \beta^{B}\right)$ is determined by constraints as opposed to marginal conditions, if it exists. For existence, it is sufficient that, given the effort cost function c, the outside option function $u$, and the parameters $a, b, y$, the solution for $\beta$ must be such that $\beta^{B} \in(0,1)$ and profit is positive. We assume that this is the case.

From (17), the agent's effort is a function of the outside option and does not vary with changes in the level of motivation and firm size. We have

$$
\partial x^{B} / \partial \mathrm{a}=S^{-1 \prime}(u(a)) u^{\prime}(a) \geqq 0, \text { with }=\text { if } u^{\prime}(a)=0, \text { and } \partial x^{B} / \partial \mathrm{b}, \partial x^{B} / \partial \mathrm{y}=0 .
$$

Thus, the only parametric change among motivation, productivity and firm size which impacts the agent's effort is a change in productivity and this is in effect only when the participation constraint is binding and the productivity change is general. The intuition is that when the participation constraint is binding, an increase in the agent's productivity which raises the agent's outside option induces the firm to incentivize more equilibrium effort so as to compensate the agent for the higher market option.

The optimal incentive share in the binding case can vary with firm size, productivity and motivation. Increases in motivation or firm size lead to decreases in the incentive share,

$$
\partial \beta^{\mathrm{B}} / \partial b=\left(-c^{\prime}\right) /\left(a y b^{2}\right)<0 \text { and } \partial \beta^{\mathrm{B}} / \partial y=\left(-c^{\prime}\right) /\left(a b y^{2}\right)<0
$$

The effect of $a$ on the incentive share is given by

$$
\partial \beta^{\mathrm{B}} / \partial a=c^{\prime \prime} S^{-1 \prime} u^{\prime}-c^{\prime} / b
$$

The sign of this derivative can be written as

$$
\operatorname{sign} \partial \beta^{\mathrm{B}} / \partial a=\operatorname{sign}\left(\left(c^{\prime \prime} / c^{\prime}\right)(d x / d u) u^{\prime}-1 / b\right)
$$

Thus, the incentive share tends to increase with productivity if the rate of increase of marginal cost is great, if the response of the outside option is great with an increase in agent productivity, and if the motivation parameter is large and conversely. Whence, productivity and the sensitivity of the contract can be substitutes or complements. In particular, if human capital is firm specific, the incentive share decreases if there is an increase in productivity and a substitute relationship obtains.

Using (17) and (18), the firm's profit as a function of $(a, b)$ is

$$
\pi^{B}=a y S^{-1}(u(a))-c^{\prime}\left(S^{-1}(u(a))\right) S^{-1}(u(a)) / b
$$

The changes in profit associated with $\mathrm{a}$ and $\mathrm{b}$ are

$$
\begin{gathered}
\pi_{a}^{B}=y S^{-1}(u(a))+S^{-1 \prime}(u(a)) u^{\prime}(a)\left[a y-G\left(S^{-1}(u(a)) / b\right]\right. \text { and } \\
\pi_{b}^{B}=c^{\prime}\left(S^{-1}(u(a)) S^{-1}(u(a)) / b^{2}\right.
\end{gathered}
$$

respectively.

As in the non-binding case, let us again explore the relative marginal profits of productivity increases versus increases in motivation,

$$
\pi_{a}^{B}-\pi_{b}^{B}=y S^{-1}(u(a))+S^{-1 \prime}(u(a)) u^{\prime}(a)\left[a y-G\left(S^{-1}(u(a)) / b\right]-c^{\prime}\left(S^{-1}(u(a)) S^{-1}(u(a)) / b^{2}\right.\right.
$$

We have

Proposition 2: Let the participation constraint be binding. Then $\pi_{a}^{B}-\pi_{b}^{B}$ is increasing in firm size and motivation. 
If training is firm specific, then higher productivity has no effect on $\pi_{a}^{B}-\pi_{b}^{B}$.

There are greater gains through training than through motivation as the firm becomes larger and as the agent becomes more motivated. How increased training affects this difference depends on specific information on the forms of $c$ and $u$. For additional training and the resultant increase in productivity to impact the relative importance of training in revenue generation, it is necessary for human capital to be non-firm specific or general. Again the relative impact of training versus motivation is greater in larger firms with very motivated employees.

To determine the nature of the relationship between $a$ and $b$ with regard to the effect of each measure on the revenue of the other measure, we compute

$$
\pi_{a b}^{B}=\left(1 / b^{2}\right)\left[u^{\prime} S^{-1 \prime} G\left(S^{-1}\right)\right] \geqq 0
$$

It is interesting to note that if $u^{\prime}=0$, then the two measures are equilibrium independents in revenue, whereas if $u^{\prime}$ > 0 , they are equilibrium complements. This observation allows us to state

Proposition 3: Let the participation constraint be binding. For motivation to affect the marginal revenue of productivity increases, it is necessary that productivity increases not be of the firm specific human capital type in that increases must improve the agent's outside option. When $a$ does increase the outside option, it is a strategic complement of $b$ in revenue.

In Proposition 3, the participation constraint is binding as the outside option increases. The latter increase induces increases in the marginal revenue of each measure, as the other measure is increased. If the outside option does not increase with productivity (i.e., firm specific productivity), then these effects are absent. The reason is that for $\pi_{b}$ $\left(\pi_{a}\right)$ to be impacted by variations in $a(b)$, it is necessary that a impacts $x^{B}$. The latter is true only when the outside option is increasing in $a$. This result is quite interesting. It says that a necessary condition for productivity and motivation to be strategic complements is that productivity is non-firm specific, when the firm is paying the outside option. The rising outside option would reduce profit other things equal. When this occurs, motivation measures serve the role of alleviating that revenue loss and, by doing so, the marginal revenue of each measure is enhanced. If the outside option does not rise, then motivation cannot confer this benefit on the firm, and strategic independence between the two variables results.

Table 1 Summarizes and compares the comparative statics between the binding and non-binding cases

\begin{tabular}{lll}
\hline & Non-binding Participation & Binding Participation \\
\hline$\beta$ & $\begin{array}{l}\text { Increasing, decreasing or constant in } \\
\text { a,b,y depending on c(x). }\end{array}$ & $\begin{array}{l}\text { Decreasing in b,y. Increasing, constant or } \\
\text { decreasing in a. Increasing in a if } \\
\text { elasticity of } \mathrm{c}(\mathrm{x}) \text { is large, } \mathrm{u} \text { ' large, or } \mathrm{b} \\
\text { large and conversely. It is decreasing in a } \\
\text { if } \mathrm{u}^{\prime}=0 .\end{array}$ \\
\hline $\mathrm{x}$ & Increasing in a,b,y. & $\begin{array}{l}\text { Depends only on } \mathrm{u}(\mathrm{a}) . \text { Increasing in a } \\
\text { only if u' }>0\end{array}$ \\
\hline$\pi_{\mathrm{a}-\pi_{\mathrm{b}}}$ & $\begin{array}{l}\text { Increasing in b and } \mathrm{y}, \text { if } \mathrm{b} \text { is greater } \\
\text { than or equal to a, and it is increasing, } \\
\text { decreasing or constant in a as b is greater } \\
\text { than, less than or equal to a. }\end{array}$ & $\begin{array}{l}\text { Increasing in b and y and invariant in a if } \\
\text { human capital is firm specific. }\end{array}$ \\
\hline$\pi_{\mathrm{ab}}$ & positive & $\begin{array}{l}\text { Positive for general and zero for firm } \\
\text { specific human capital. }\end{array}$ \\
\hline
\end{tabular}

The key differences between the binding and non-binding cases are as follows. First in the binding case, compensation and productivity and compensation and motivation can be both substitutes, complements or independents depending on the form of effort cost. In the binding case, compensation and motivation are substitutes, whereas compensation and productivity can be substitutes, complements or independents depending on the elasticity of effort cost, the level of motivation and the change in the outside option. If productivity is firm specific, they are substitutes. Second, in the non-binding case, effort increases in productivity and motivation, whereas in the binding case it only changes with changes in the outside option brought about by general training. In the non-binding case, motivation and productivity are complements, and the same is true in the binding case with general productivity. The 
binding case makes motivation and productivity independents if productivity is firm specific.

\section{Investment in Human Capital and Motivational Measures in a Stochastic Power Function Example}

Suppose that the productivity parameter can take on two possible values, $a \in\left\{a_{L}, a_{H}\right\}$, $a_{H}>a_{L}$, and likewise assume that the motivation variable can assume either a high or low value, $b \in\left\{b_{L}, b_{H}\right\}, b_{H}>b_{L}$. The firm can control the probability that each of these measures would take on the high or the low value. Let Prob $\left(a_{H}\right)=\theta_{a} x_{a}$ and Prob $\left(b_{H}\right)=\theta_{b} x_{b}, \theta_{i} \in(0,1), x_{i} \in[0,1), i=a, b$. The variable $x_{i}$ represents the principal's effort in attempting to increase the agent's productivity or motivation level, $i=a, b$. The parameter $\theta_{i}$ represents the principal's technology for implementing worker education or worker motivation, $i=a, b$. Greater $\theta_{i}$ means that the principal becomes more efficient at education or motivation.

For tractability purposes, we will use specific power function (PF) functional forms for costs, in what follows. Effort cost in the production of cash flow is given by $c(x)=c x^{v} / v$ with $v \geqq 2$ and $c>0$. Note that we require $v \geqq 2$ so that A. 1 is met and marginal effort cost is convex. The costs of $x_{i}$ are given by $c_{i} x_{i}^{v_{i}} / v_{i}$ with $v_{i}>1$ and $c_{i}>0, i$ $=a, b$. For these costs, we can use the above theoretical analysis to write expected equilibrium profit, for the cases of a non-binding and a binding participation constraint. We will term this specialization the PF model.

The PF model allows us to extend our knowledge of bounds on the principal's optimal $\beta$. We saw in Lemma 2 that in the general version with a non-binding participation constraint, $\beta$ is bounded from above by $1 / 2$. The PF model allows us to state

Lemma 3: In the PF model, we have that $\beta \geqq 1 / \mathrm{v}$, with equality if the participation constraint is non-binding.

Combining Lemmas 2 and 3, we see that $\beta$ is generally bounded from above by one half. In the PF model, if the participation constraint is non-binding, it is at its lower bound of $1 / v, v \geqq 2$. It is between $1 / 2$ and $1 / v$ when the participation constraint is binding.

Using the PF model of costs, we can specialize the non-binding equilibrium. When the participation constraint is non-binding, the solutions for $\beta, x$, and profit in period one are given by

$$
\begin{gathered}
\beta^{N}=(1 / v), x^{N}\left(a_{i}, b_{j}\right)=\left(\left(a_{i} b_{j} y\right) /(v c)\right)^{1 /(v-1)}, \\
\text { and } \left.\pi^{N}\left(a_{i}, b_{j}\right)=a_{i}^{v /(v-1)} b_{j}^{1 /(v-1)}\left((v-1) y^{v /(v-1)}\right) /\left(v^{v /(v-1)} c^{1 /(v-1)}\right)\right)-\frac{\sum_{k=a}^{b} c_{k} x_{k}^{v_{k}}}{v_{k}}, i, j=L, H,
\end{gathered}
$$

respectively.

Note that the principal's optimal incentive payment, $\beta$, is a constant function with respect to all parameters except for the cash flow effort cost elasticity and that it is decreasing in that elasticity. The agent's effort increases in both $a_{i}, b_{j}, v$, and $y$, while it decreases in $c$. Cash flow effort increases in its effort cost elasticity $v$, whereas the sensitivity of the contract decreases in $v$. Profit is, other things equal, is a convex function of $a_{i}$ and a concave function of $b_{j}$. That is, the level of productivity has a more powerful effect than that of the level of motivation.

Equilibrium expected profit from a period zero perspective is

$$
\mathrm{E}\left(\pi^{N}\right)=k_{N} E\left(a^{\frac{v}{v-1}}\right) E\left(b^{\frac{1}{v-1}}\right)-\sum_{i=a}^{b} c_{i} x_{i}^{v_{i}} / v_{i} \text {, where } k_{N} \equiv\left((v-1) y^{v /(v-1)}\right) /\left(v^{\frac{v}{v-1}} c^{\frac{1}{v-1}}\right)
$$

At period zero, in the precontracting stage, the firm maximizes (22) over a selection of $x_{i}$, $i=a, b$. Necessary conditions for a maximum include

$$
\begin{gathered}
\partial \mathrm{E}\left(\pi^{N}\right) / \partial x_{a}=k_{N} \theta_{a}\left(a_{H}^{\frac{v}{v-1}}-a^{\frac{v}{v-1}}\right) E\left(b^{1 /(v-1}\right)-c_{a} x_{a}^{v_{a}-1}=0 \\
\text { and } \partial \mathrm{E}\left(\pi^{N}\right) / \partial x_{b}=k_{N} \theta_{b}\left(b_{H}^{\frac{1}{v-1}}-b_{L}^{\frac{1}{v-1}}\right) E\left(a^{v /(v-1}\right)-c_{b} x_{a}^{v_{b}-1}=0 \text { (Note 13) }
\end{gathered}
$$

The principal's investment choices in motivational measures and human capital are described by (23) and (24). The marginal revenue of each measure is greater the greater is the transformed spread (implying a higher variance or diversity) between high and the low measure levels and the greater is the expectation of the transformed alternative measure. When the spreads of the distribution of productivities and possible motivation levels are great and the expectations of these stochastic variables are high, the returns to investment in education and motivation are each high. Moreover, the investment levels $x_{a}$ and $x_{b}$ are strategic complements in expected profit:

$$
\partial^{2} E\left(\pi^{N}\right) / \partial x_{a} \partial x_{b}=k_{N} \theta_{a} \theta_{b}\left(a_{H}^{\frac{v}{v-1}}-a_{L}^{\frac{v}{v-1}}\right)\left(b_{H}^{\frac{1}{v-1}}-b_{L}^{\frac{1}{v-1}}\right)>0
$$


The comparative statics of the non-binding equilibrium are straightforward (Note 14).

Comparative Statics of the PF Non-binding Case: If the participation constraint is non-binding, then $\partial x_{a} / \partial \theta_{i}$, $\partial x_{b} / \partial \theta_{i}>0, i=a, b$. Further, $\partial x_{i} / \partial c, \partial x_{i} / \partial c_{j}<0$ and $\partial x_{i} / \partial y>0, i, j=a, b$.

These results tell us that in firms where there are advancements in the efficiency of training or motivational techniques, we should observe more training and more motivational measures. Examples of improved efficiency in training might include the emergence of highly effective online interactive instruction. Examples of technological improvement in motivation might include the case where the firm discovers a new technology of communication between managers and employees which improves the ability of managers to communicate the goals of the firm to the employees or a new perk which raises gross utilities. As expected, increases in the cost parameters, including cash flow effort cost and the costs of raising $x_{i}$, all decrease the firm's optimal investment efforts, while increases in firm size, $y$, have the effect of raising both types of investments.

Given the PF forms for costs and a binding participation constraint, the solutions for $\beta, x$, and profit at period 1 are given by

$$
\begin{gathered}
\beta^{B}\left(a_{i}, b_{j}\right)=\frac{c^{\frac{1}{v}}}{b_{j} a_{i} y}\left(\frac{u\left(a_{i}\right) v}{v-1}\right)^{\frac{v-1}{v}}, x_{b}\left(a_{i}\right)=\left(\frac{u\left(a_{i}\right) v}{c(v-1)}\right)^{\frac{1}{v}} \\
\pi^{B}\left(a_{i}, b_{j}\right)=k_{B} u^{1 / v} a_{i}-\frac{v}{v-1} \frac{u\left(a_{i}\right)}{b_{j}} \sum_{k=a}^{b} c_{k} x_{k}^{v_{k}}, i, j=L, H, \text { where } k_{B}=y\left(\frac{v}{c(v-1)}\right)^{\frac{1}{v}}
\end{gathered}
$$

The agent's effort is decreasing in the cost parameter $c$ and the cost elasticity parameter $v$. The negative effect of changes in $v$ on cash flow effort is in contrast to the non-binding case, where cash flow effort is increasing in its cost elasticity. As pointed out in the general model, effort is not a function of motivation and it increases in productivity only if the outside option increases in $a$.

The principal's optimal incentive payment, $\beta$, is increasing in the effort cost parameter $c$. As pointed out in the general model, it is decreasing in the motivation parameter and the firm size parameter. How $\beta$ reacts to changes in the effort cost elasticity depends on magnitudes of $c, u\left(a_{i}\right)$ and $v$ (Note 15). Finally, $\beta$ is increasing or decreasing in the productivity parameter according to whether

$$
u^{\prime}\left(a_{i}\right) \frac{a_{i}}{u\left(a_{i}\right)} \geq \frac{v}{v-1} \leqq 2
$$

In cases where the elasticity of the outside option is greater than one and, in fact, greater than $v /(v-1) \leqq 2$, productivity is a complement of the sensitivity of the contract. It is a substitute otherwise. The term $v /(v-1)$ is decreasing in the elasticity of cash flow effort cost, so that large elasticity of cash flow effort cost contributes to a positive relationship between the incentive share and the productivity, and conversely. If training is firm specific, $u^{\prime}$ $=0$, the elasticity is zero and productivity is a substitute of sensitivity.

The surplus function is specialized to $\left.S(x)=c x^{v}(v-1) / v\right)$, and the necessary condition for a binding participation constraint, A.2, is that

$$
c\left(\frac{v-1}{v}\right)>u\left(a_{H}\right)
$$

Condition (26) must be met for for $a_{i}, i=L, H$, but because $v \geqq 2$, it suffices that it be met for $i=H$.

From a period zero perspective, the principal's expected profit is given by

$$
E(\pi)=k_{B} E\left(u^{\frac{1}{v}} a\right)-\frac{v}{v-1} E(u(a)) E\left(b^{-1}\right)-\sum_{i=a}^{b} \frac{c_{i} x_{i}^{v_{i}}}{v_{i}} .
$$

The necessary conditions for a maximum include

$$
\frac{\partial E(\pi)}{\partial x_{a}}=k_{B} \theta_{a}\left(a_{H} u\left(a_{H}\right)^{\frac{1}{v}}-a_{L} u\left(a_{L}\right)^{\frac{1}{v}}-\frac{v}{v-1} \theta_{a}\left(u\left(a_{H}\right)-u\left(a_{L}\right)\right) E\left(b^{-1}\right)-c_{a} x_{a}^{v_{a}-1}=0\right.
$$




$$
\text { and } \frac{\partial E(\pi)}{\partial x_{b}}=\frac{v}{v-1} E(u(a)) \theta_{b}\left(b_{H}^{-1}-b_{L}^{-1}\right)-c_{b} x_{b}^{v_{b}-1}=0 \text { (Note 16) }
$$

Notice that these conditions are asymmetric, unlike the case where the participation constraint is non-binding. The marginal profitability of $x_{a}$ now contains a marginal loss term, $-\frac{v}{v-1} \theta_{a}\left(u\left(a_{H}\right)-u\left(a_{L}\right)\right) E\left(b^{-1}\right)<0$, which accounts for the loss in profit due to the fact that an increase in $x_{a}$ can increase the expected outside option in the non-firm specific case. This loss is greater the lower is the expected level of motivation, the smaller is the elasticity of effort cost with respect to effort, the better is the technology of education, and the greater is the increase in the outside option in going from a low productivity worker to a high productivity worker. The marginal benefit term $k_{B} \theta_{a}\left(a_{H} u\left(a_{H}\right)^{\frac{1}{v}}-a_{L} u\left(a_{L}\right)^{\frac{1}{v}}\right.$ accounts for the rise in the cash flow with a higher expected productivity agent. It is conceivable that the loss created by the increase in the outside option, $-\frac{v}{v-1} \theta_{a}\left(u\left(a_{H}\right)-u\left(a_{L}\right)\right) E\left(b^{-1}\right)$, dominates the latter benefit so as to create a corner solution, where the firm does not engage in education measures. Conditions for a large loss are given above. In the firm specific case, this loss term is nonexistent.

The marginal profitability of $x_{b}$ has a marginal benefit term which can can be rewritten as $-\frac{v}{v-1} E(u(a)) \theta_{b}\left(b_{L}^{-1}-\right.$ $\left.b_{H}^{-1}\right)>0$. This represents the reduction in loss generated by increasing the probability of $b_{H}$ and lowering the probability of $b_{L}$ in the situation where the participation constraint is binding. This points out that the direct marginal benefit of motivational measures is to satisfy the binding participation constraint and that the greater is the expected outside option, the greater is that benefit. Note that the composite parameter $k_{B}=y\left(\frac{v}{c(v-1)}\right)^{\frac{1}{v}}$, which is increasing in the high output and decreasing in the effort cost efficiency parameter $c$, does not directly enter the marginal profitability of $x_{b}$. In the strategic independent case (i.e., firm specific human capital), this will lead to changes in $y$ and $c$ having no affect on motivational measures, $x_{b}$. Note that the loss reduction is greater the better is the technology of motivation, the lower is the effort cost elasticity $v$, the higher is the outside option and the greater the spread between the $b_{i}$. Finally, note that the only way that changes in education investment can impact the marginal benefit of motivational investment is for the former investment to raise the expected outside option. This can only happen in the non-firm specific case. Thus, the two investments are strategic complements in profit only if $u\left(a_{H}\right)>u(L)$ and independents in the firm specific case:

$$
\frac{\partial^{2} E(\pi)}{\partial x_{a} \partial x_{b}}=\frac{v}{v-1} \theta_{a} \theta_{b}\left(u\left(a_{H}\right)-u\left(a_{L}\right)\right)\left(b_{L}^{-1}-b_{H}^{-1}\right) \geqq 0 \text { with }=\text { if } u\left(a_{H}\right)=u\left(a_{L}\right)
$$

The comparative statics of principal's problem with a binding participation constraint depend on whether education is firm specific or general, as the results change when the outside option is constant in ability. We have

Comparative Statics of the PF Binding Case: Suppose that the participation constraint is binding. We have

(i) $\partial x_{i} / \partial \theta_{i}>0, I=a, b$, and $\partial x_{i} / \partial \theta_{j} \geqq 0, i \neq j, i, j=a, b$, with equality iff $u^{\prime}=0$.

(ii) $\partial x_{i} / \partial c_{i}<0, \mathrm{i}=\mathrm{a}, \mathrm{b}$, and $\partial x_{i} / \partial c_{j} \leqq 0, i \neq j, i, j=a, b$, with equality iff $u^{\prime}=0$.

(iii) $\partial x_{a} / \partial c<0$ and $\partial x_{i} / \partial y>0$, while $\partial x_{b} / \partial c \leqq 0$ and $\partial x_{b} / \partial y \geqq 0$, with equality iff $u^{\prime}=0$.

A binding participation constraint introduces changes in our comparative static results from the non-binding case, only if training is firm specific. The new results are as in the following. Due to the strategic independence of $x_{i}$, all cross effects of changes in $\theta_{i}$ and $c_{i}$ are zero. Here, the marginal profitability of $\theta_{i}$ and $c_{i}$ only affect $x_{i}$. Moreover, changes in $y$ and $c$ do not induce changes in $x_{b}$, because effort cost and firm size changes only affect the 
marginal profitability of education.

The elimination of cross effects in the firm specific case is interesting. For the cases of technological improvements and investment cost shifts, we have that these changes lead to different empirical predictions depending on whether educational investment is firm specific or not.

\section{A Tighter Labor Market in the PF Binding Case With Non-firm Specific Human Capital}

In the binding case where education is non-firm specific, another comparative static question arises. How does the firm optimally respond to a change in the market's assessment of the employee's outside option in reaction to a greater productivity level? We formulate this question by assuming that

$$
u\left(a_{L}\right)=u \text { and } u\left(a_{H}\right)=u+\Delta,
$$

where $u$ is a constant. The parameter $\Delta$ will measure the response of the market, with respect to the outside option, to a higher productivity level. Greater $\Delta$ means a greater degree of market response to the higher productivity or a "tighter" labor market. Under this formulation, the first order conditions (27) and (28) are revised to read

$$
\begin{gathered}
\frac{\partial E(\pi)}{\partial x_{a}}=k_{B} \theta_{a}\left(a_{H}(u+\Delta)^{\frac{1}{v}}-a_{L} u^{\frac{1}{v}}\right)-\frac{v}{v-1} \theta_{a}(\Delta) E\left(b^{-1}\right)-c_{a} x_{a}^{v_{a}-1}=0 \\
\frac{\partial E(\pi)}{\partial x_{b}}=-\frac{v}{v-1}\left(\theta_{a} x_{a}(u+\Delta)+\left(1-\theta_{a} x_{a}\right) u\right) \theta_{b}\left(b_{H}^{-1}-b_{L}^{-1}\right)-c_{b} x_{b}^{v_{b}-1}=0
\end{gathered}
$$

The direct impact of a change in $\Delta$ on $\partial E(\pi) / \partial x_{a}$ is

$$
\frac{y\left(\frac{v}{c(v-1)}\right)^{1 / v} \theta_{a} a_{H}(u+\Delta)^{\frac{1}{v}-1}}{v}-\frac{v}{v-1} \theta_{a} \mathrm{E}\left(b^{-1}\right)<0
$$

and the direct impact of a change in $\Delta$ on $\partial E(\pi) / \partial x_{b}$ is shown to be

$$
-\frac{v}{v-1}\left(\theta_{a} x_{a}\right) \theta_{b}\left(b_{H}^{-1}-b_{L}^{-1}\right)>0
$$

In the following proposition, we show that (31) is negative, so that a rise in the responsiveness of the outside option has the predictable direct effect of decreasing the marginal profitability of educational investment. However, it increases the marginal profitability of motivational investment. Given that the two investments are complementary, in the non-firm specific education case, these two opposing effects could lead to counter intuitive results. Casual reasoning would suggest that a rise in $\Delta$ would lead to a decrease in educational investment and an increase in motivational investment. However, it turns out that these results may not obtain under some admissible parametric specifications.

The signs of $\partial x_{i} / \partial \Delta$ can be described by

$$
\begin{gathered}
\operatorname{sign}\left(\partial x_{a} / \partial \Delta\right)=\operatorname{sign}\left\{\left(v_{b}-1\right) c_{b} x_{b}^{v_{b}-2}\left[\frac{a_{H} y\left(\frac{v}{\left(\frac{v}{c(v-1)}\right)^{\frac{1}{v}}}\right)}{v(\Delta+u)^{\frac{v}{v-1}}}-\frac{v}{v-1} E\left(b^{-1}\right)+\left[\frac{v}{v-1} \theta_{b}\left(b_{L}^{-1}-b_{H}^{-1}\right)\right]^{2} \theta_{a} x_{a} \Delta\right\}\right. \\
\text { and } \operatorname{sign}\left(\partial x_{b} / \partial \Delta\right)=\operatorname{sign}\left\{\left[\frac{a_{H} y\left(\frac{v}{c(v-1)^{\frac{1}{v}}}\right)}{v(\Delta+u)^{\frac{v}{v-1}}}-\frac{v}{v-1} x_{a} E\left(b^{-1}\right)\right] \theta_{a} \Delta+\left(v_{a}-1\right) c_{a} x_{a}^{v_{a}-1}\right\}
\end{gathered}
$$

The first term of (33) emanates from the direct negative effect on $x_{a}$ (as per result (31)) and the second term comes from the positive cross effect, of a change in $\Delta$. Simulations in the proof of the following Proposition 4 show that for quadratic costs of $x_{i}$ the sign of $\partial x_{a} / \partial \Delta$ can be positive for small $\Delta$ and negative for larger $\Delta$. The second positive term of (34) comes from the direct effect of a change in $\Delta$, while the first negative term comes from the cross effect of a change in $\Delta$. Again, we show in the proof of the following proposition that the sign of $\partial x_{b} / \partial \Delta$ can be positive for small $\Delta$ and negative for larger $\Delta$.

We have

Proposition 4: A greater degree of market response of the outside option to an increase in the productivity of the agent results in a decrease in the marginal profitability of educational investment and an increase in the marginal 
profitability of motivational investment. However, this change can result in both increases or decreases in the optimal amount of educational and motivational investments, depending on parameter values.

The key factor in the above unexpected results is the cross effect produced by a change in the degree of the market response. A rise in $\Delta$ can increase educational investment if the positive cross effect from motivational investment is large enough and it can lower motivational investment if the negative cross effect from educational investment is great enough. Thus, more responsiveness of the outside option can lead to counter intuitive results for these two types of investments, due to interaction effects. This fact should inform empirical work attempting to test on the basis of direct effects only. Interactive effects can matter so as to reverse the impact of direct effects on each type of investment. A model not containing both measures does not pick up these interactions.

Finally, while a "tighter labor market" can lead to unexpected investment changes, it is clear that such a tightening will lead to lower profit for the firm. Using the envelope theorem, we have, in equilibrium, that

$$
\frac{\partial E(\pi)}{\partial \Delta}=x_{a}\left[\frac{y\left(\left(\frac{v}{c(v-1)}\right)^{\frac{1}{v}}\right) \theta_{a} a_{H}(\Delta+u)^{\frac{1}{v}-1}}{v}-\frac{v}{v-1} \theta_{a} E\left(b^{-1}\right)\right]<0
$$

from (31). A firm with a binding participation constraint and non-firm specific training will always suffer from a tighter labor market, but may expand or contract motivational and educational investments in unpredictable ways as a result of a tighter labor market.

\section{Motivation Modeled as a Measure Which Reduces Effort Cost}

So far we have modeled motivation as increasing gross utility. Are results altered if motivation reduces effort cost? This modeling change does not affect any of our above results if the participation constraint is not binding. In the binding case, there are definite changes. It is easy to show that Lemma 1 holds for this case such that the optimal $\alpha=$ 0 .

First consider the general model with the levels of productivity and motivation exogenous. Let us rewrite the participation and incentive compatibility constraints under this new format with effort cost given by $c(x) / \gamma$, where $\gamma>$ 1 denotes motivation measures. In equilibrium, we have that

$$
\begin{gathered}
\gamma \beta a y x-c(x)-\gamma u(a)=0 \\
\text { and } \gamma \beta a y-c^{\prime}(x)=0
\end{gathered}
$$

Assumption A.2, which is necessary for the satisfaction of the participation constraint, becomes

A. $2^{\prime} S(1)>\gamma u(a)$.

Using the definition of $S(x)$, we can rewrite (35) using (36) to state

$$
\begin{gathered}
x^{B c}=S^{-1}(\gamma u(a)) \\
\text { and } \beta^{B c}=\frac{c^{\prime}\left(S^{-1}(\gamma u(a))\right.}{\gamma a y}
\end{gathered}
$$

where the superscript " $B C$ " denotes binding participation constraint and cost reduction motivation. Comparing (17) to (37) and (18) to (38) we see that $\gamma$ unlike $b$ multiplies $u(a)$ in (37)-(38). Because $\gamma$ now affects $x^{B c}$, the previous independence result will be changed. For this case,

$$
\frac{\partial x^{B c}}{\partial a}=S^{-1^{\prime}}(\gamma u(a)) \gamma u^{\prime} \geqq 0, \text { with }=\text { if } u^{\prime}(a)=0, \frac{\partial x^{B c}}{\partial \gamma}=S^{-1^{\prime}}(\gamma u(a)) u>0 \text {, and } \frac{\partial x^{B c}}{\partial y}=0
$$

In comparison to the utility enhancing case, both $a$ and $y$ have analogous effects on effort, but an increase in $\gamma$ has a positive effect on effort, while $b$ does not affect effort. The incentive share has the following comparative statics

$$
\operatorname{sign}\left(\frac{\partial \beta^{B c}}{\partial a}\right)=\operatorname{sign}\left(\frac{c^{\prime \prime}}{c^{\prime}} \frac{d x}{d u} u^{\prime}-\frac{1}{\gamma}\right) \text {, sign }\left(\frac{\partial \beta^{B c}}{\partial \gamma}\right)=\operatorname{sign}\left(\frac{c^{\prime \prime}}{c^{\prime}} \frac{d x}{d u} u^{\prime}-\frac{1}{\gamma}\right) \text {, and } \frac{\partial \beta^{B c}}{\partial \gamma}=-\frac{c^{\prime}}{\gamma a y^{2}}<0
$$

The effects of changes in $a$ and $y$ are analogous, but the motivation parameter in the cost reduction case now has an effect similar to changes in a. Greater $\gamma$ raises the incentive share when the rate of increase of marginal cost is great, if the level of the outside option is large, and if the motivation parameter is large and conversely.

Using (37) and (38) the firm's equilibrium profit with cost reduction motivation is given by 


$$
\pi^{B c}=a y S^{-1}(\gamma u(a))-\frac{c^{\prime}\left(S^{-1}(\gamma u(a))\right) s^{-1}(\gamma u(a))}{\gamma}
$$

Suppose that the organization could choose between motivation measures which enhance utility and those which would discount effort cost. Ignoring costs, which would be more effective in raising revenue, in equilibrium? We have the following result.

Proposition 5: Let the participation constraint be binding. Then for each $b=\gamma$, we have

$$
\frac{\partial \pi^{B c}}{\partial \gamma} \geq \frac{\partial \pi^{B}}{\partial b} \text { as } y \geq \frac{1}{<\gamma a}\left(c^{\prime}\left(S^{-1}(\gamma u(a))\right)+\frac{c \prime \prime\left(S^{-1}(\gamma u(a))\right) S^{-1}(\gamma u(a))}{\gamma}\right)
$$

Proposition 5 tells us that measures which discount effort cost are more effective for the firm, in terms of revenue enhancement, if the reward for successful performance, $y$, is above a cutoff level, and that measures which enhance utility are more effective if it is below that cutoff. If we think of $y$ as firm size, then small firms should focus on motivation measures which raise utility and larger firms should focus on motivation measures which reduce effort cost, in environments where the participation constraint is binding and revenue enhancement is the goal..

As with $\mathrm{b}$, let $\gamma$ take on two values $\left.\gamma \in\left\{\gamma_{L}, \gamma_{H}\right\}\right\}$ with $\gamma_{H}>\gamma_{L}>1$. Moreover, let Prob $\left(\gamma_{H}\right)=\theta_{\gamma} x_{\gamma}$. The PF specialization with a binding participation constraint results in the following equilibrium solutions.

$$
\begin{gathered}
\beta\left(a_{i}, \gamma_{j}\right)=\frac{c^{\frac{1}{v}}}{\gamma_{j}^{\frac{1}{v}} a_{i} y}\left(\frac{u\left(a_{i}\right) v}{v-1}\right)^{(v-1) / v}, x\left(a_{i}, \gamma_{j}\right)=\left(\frac{\gamma_{j} u\left(a_{i}\right) v}{c(v-1)}\right)^{1 / v} \\
\left.\pi\left(a_{i}, b_{j}\right)=k_{B} u^{1 / v} \gamma_{j}^{1 / v} a_{i}-\frac{u\left(a_{i}\right) v}{v-1}-\right) \sum_{k=a}^{\gamma} \frac{c_{k} x_{k}^{v_{k}}}{v_{k}}, i, j=L, H, \text { where } k_{B}=y\left(\frac{v}{c(v-1)}\right)^{\frac{1}{v}}
\end{gathered}
$$

As in the case where motivation measures enhance utility, we see that the incentive share, $\beta$, is decreasing in $\gamma_{i}$ and can be decreasing or increasing in the productivity level $a_{i}$ depending on condition (25) above. Effort is increasing in $\gamma$ and decreasing in $c$, while it is increasing in $a_{i}$ only if $u^{\prime}>0$. As in the previous case, effort is decreasing in $v$.

Expected profit from a time zero perspective becomes

$$
E(\pi)=k_{B} \theta_{a} E\left(a u(a)^{\frac{1}{v}}\right) E\left(\gamma^{\frac{1}{v}}\right)-\frac{v}{v-1} E(u(a))-\sum_{i=a}^{\gamma} \frac{c_{i} x_{i}^{v_{i}}}{v_{i}}
$$

We have that

$$
\begin{gathered}
\frac{\partial E(\pi)}{\partial x_{a}}=k_{B} \theta_{a}\left(a_{H} u\left(a_{H}\right)^{1 / v}-a_{L} u\left(a_{L}\right)^{1 / v}\right) E\left(\gamma^{\frac{1}{v}}\right)-\frac{v}{v-1} \theta_{a}\left(u\left(a_{H}\right)-u\left(a_{L}\right)\right)-c_{a} x_{a}^{v_{a}-1}=0 \\
\text { and } \frac{\partial E(\pi)}{\partial x_{\gamma}}=k_{B} \theta_{\gamma}\left(\gamma_{H}^{\frac{1}{v}}-\gamma_{L}^{\frac{1}{v}}\right) E\left(a u(a)^{\frac{1}{v}}\right)-c_{\gamma} x_{\gamma}^{v_{\gamma}-1}=0
\end{gathered}
$$

The marginal profitability of training measures is increasing in the spread between the high and low productivity measures, and it is enhanced by a greater expected motivation level. It is also decreased by an increase in the outside option or an increase in the efficiency of training, $\theta_{a}$. The marginal profitability of motivation measures is increasing in the spread between the high and low motivation levels and the expected productivity levels. From (41) and (42), measures $x_{a}$ and $x_{\gamma}$ are complements in profit

$$
\frac{\partial^{2} E(\pi)}{\partial x_{a} \partial x_{\gamma}}=k_{B} \theta_{a}\left(a_{H} u\left(a_{H}\right)^{1 / v}-a_{L} u\left(a_{L}\right)^{1 / v}\right) \theta_{\gamma}\left(\gamma_{H}^{\frac{1}{v}}-\gamma_{L}^{\frac{1}{v}}\right)>0
$$

The positive cross effect, regardless of firm specificity, marks a difference between motivation which lowers effort cost and that which enhances utility. In the present case, it is not necessary for the agent's productivity to push up the outside option in order for there to be a positive effect of motivation on the marginal profitability of education and vice versa.

We can show that the effort cost reducing model of motivation has all of the same properties as in the binding case 
with non-firm specific human capital and utility enhancing motivation. We have

Proposition 6: In the PF model, suppose that the participation constraint is binding and that motivation reduces effort cost. Then regardless of whether education is firm specific or non-firm specific, we have $\frac{\partial x_{a}}{\partial \theta_{a}}, \frac{\partial x_{\gamma}}{\partial \theta_{a}}>0$ and $\frac{\partial x_{a}}{\partial \theta_{\gamma}}, \frac{\partial x_{\gamma}}{\partial \theta_{\gamma}}>0$. Moreover, $\frac{\partial x_{i}}{\partial c}, \frac{\partial x_{i}}{\partial c_{j}}<0$, and $\frac{\partial x_{i}}{\partial y}>0, i, j=a, \gamma$. Further, all of the results of Proposition 4 regarding changes in the tightness of the labor market hold for the case where motivation reduces effort cost.

In the class of problems in which motivation reduces effort cost, we no longer have the result that firm specific human capital investment results in strategic independence of educational and motivational investments, when the participation constraint is binding. In this case, the two investments are complements and we have the usual comparative statics, regardless of the degree of firm specificity of education. We see that whether motivation affects effort cost or gross utility definitely matters for predictions in the binding case. Finally, with a binding participation constraint, a tighter labor market can lead to increases or decreases in either type of investment as in the previous model. For quadratic investment costs, simulations in the proof of Proposition 6 show that $x_{i}, i=a$, $\gamma$, can be increasing for a small tightening of the labor market (small $\Delta$ ) and decreasing for a greater magnitude tightening of the labor market (large 4 ).

\section{Conclusion}

This paper has examined the interaction of training measures and motivation measures in an agency context with risk neutral actors and limited liability. We show that how the measures interact, how they affect revenue and profit, and how they interact with the optimal contract depend on whether the firm's participation constraint is binding or not, on the firm specificity of training measures, and on whether motivation measures enhance utility or reduce effort cost. The latter three factors also impact the comparative statics of firm size, technological progress and cost shifts. We also show that when both training and motivation are simultaneously employed by the firm, the impact of a tighter labor market leads to predictable effects on the marginal profitability of these measures but it can lead to counter intuitive effects on the employment of these measures, due to interactive considerations.

\section{References}

Association for Talent Development. (2016). State of the Industry Report. Retrieved from https://www.td.org/Store/Product?ProductId=15672339

Becker, G. (1962). Investment in Human Capital: A Theoretical Analysis. The Journal of Political Economy, 70, 9-49.

Bernardo, A., Cai, H., \& Luo, J. (2001). Capital Budgeting and Compensation with Asymmetric Information and Moral Hazard. Journal of Financial Economics, 61, 311-344.

Bersin, J. (2014). Spending on Corporate Training Soars: Employee Capabilities Now a Priority. Retrieved from forbes.com

Besanko, D., \& Sibley, D. S. (1991). Compensation and Transfer Pricing in a Principal-Agent Model. International Economic Review, 32, 55-68.

Caramela, S. (2018, March 14). 15 Cool Job Perks that Keep Employees Happy. Business News Daily. Retrieved from https://www.businessnewsdaily.com/5134-cool-job-benefits.html

Feltham, G. A., \& Xie, J. (1994). Performance Measure Congruity and Diversity in Multi-Task Principal/Agent Relations. Accounting Review, 69, 429-453.

Garcia, D. (2014). Optimal Contracts with Privately Informed Agents and Active Principals. Journal of Corporate Finance, 29, 695-709.

Harris, M., \& Raviv, A. (1996). The Capital Budgeting Process: Incentives and Information. Journal of Finance, 51, 1139-1174.

Hirshleifer, D., \& Suh, Y. (1992). Risk, Managerial Effort, and Project Choice. Journal of Financial Intermediation, 2, 308-345.

Holmstrom, B., \& Milgrom, P. (1991). Multitask Principal-Agent Analyses: Incentive Contracts, Asset Ownership, and Job Design. Journal of Law, Economics and Organization, 7, 24-52. 
Kenrick, D. T., Griskevicius, V., Neuberg, S. L., \& Schaller, M. (2010). Renovating the pyramid of needs: contemporary extensions built upon ancient foundations. Perspectives on Psychological Science, 5, 292-314.

Kvaloy, O., \& Schottner, A. (2015). Incentives to Motivate. Journal of Economic Behavior and Organization, 116, 26-42.

Marino, A. M. (2015). Work Environment and Moral Hazard. Journal of Regulatory Economics, 48, 53-73.

Marino, A. M., \& Zabojnik, J. (2008). Work-Related Perks, Agency Problems, and Optimal Incentive Contracts. Rand Journal of Economics, 39, 565-585.

Marino, A. M., \& Ozbas, O. (2014). Disclosure of Status in and Agency Setting. Journal of Economic Behavior and Organization, 105, 191-207.

Maslow, A. H. (1970). Motivation and Personality (2nd ed.). New York, NY: Harper and Row.

Sung, J. (1995). Linearity with Project Selection and Controllable Diffusion Rate in Continuous-Time Principal-Agent Problems. Rand Journal of Economics, 26, 720-743.

\section{Notes}

Note 1. I thank my colleagues Odilon Camara, Joao Ramos and Yanhui Wu for their insightful comments. I also thank the Marshall School of Business for generous research support.

Note 2. See the (Association for Talent Development, 2016 State of the Industry Report, 2016). See also (Bersin 2014).

Note 3. See (Bersin, 2014).

Note 4. Given the complexity of having an endogenously optimal contract and two different discretionary measures, we concentrate on the complements case as opposed to a substitute case.

Note 5. This formulation is one of complementarity between motivation and the wage or between motivation and effort in the cost of effort function. That is, more motivation makes the marginal and total utility of the wage go up in the organization and it can make the marginal and total cost of effort go down in the particular organization. There is scant empirical evidence from experimental work as to the precise interaction effects. Kvaloy et al. (2015) find complementarity between the contingent wage and motivation but not between a fixed wage and motivation in one small experiment. Others have obtained mixed results (See Kosfeld et al. (2016)) so far with the interaction effects dependent on the specific setting. We will show later that the optimal contract only has contingent compensation, so that we essentially make contingent compensation and motivations complements. In any case, we take the fairly important approach of complementarity and leave it to others to analyze the substitutes case.

Note 6. See (Caramela, 2018).

Note 7. At Zinga every day is a bring your dog to work day with pet insurance and a rooftop dog park complete with treats. See (Caramela, 2018).

Note 8. It is possible that increases in some motivational measures could push up the outside option utility. However, many measures employed today are entirely firm specific. Examples come from cases where personal relationships might develop between the employee and the firm such as a special and dedicated day care staff which bonds with the employee's children, personal ties between the employee and those providing employee services, ties between a supervisor and an employee, and perks that build a corporate culture are unique to the firm.

Note 9 . We abstract from the hidden information problem wherein the agent knows a and $\mathrm{b}$ with greater precision than does the principal.

Note 10. We use the fact that a real valued twice differentiable function $f(x)$ which satisfies $f^{\prime}, f^{\prime \prime}>0$ and $f(0)=0$ also satisfies $f^{\prime}(x) x-f>0$. Moreover, if $f^{\prime}>0, f^{\prime \prime}<0$ and $f(0)=0$, then $f^{\prime}(x) x-f<0$.

Note 11. The principal's reduced problem is to choose $\beta$ so as to maximize (1- $\beta$ )bayx( $\beta$ bay). The first order condition in $\beta$ is - bayx $(\beta$ bay $)+(1-\beta)(\text { bay })^{2} x^{\prime}(\beta$ bay $)=0$. The second order condition is met: $-2(\text { bay })^{2}+$ $(1-\beta)(\text { bay })^{3} x^{\prime \prime}<0$.

Note 12. At this juncture, we do not want arbitrary assumptions about relative marginal costs of education versus motivation to cloud the endogenous impacts on revenue of these measures.

Note 13. Given our assumptions on costs, the second order conditions to the principal's problem are met if we 
assume $c_{a} c_{b}\left(v_{a}-1\right)\left(v_{b}-1\right) x_{a}^{v_{a}-2} x_{b}^{v_{b}-2}>\left[k_{N} \theta_{a} \theta_{b}\left(a_{H}^{\frac{v}{v-1}}-a_{L}^{\frac{v}{v-1}}\right)\left(b_{H}^{\frac{1}{v-1}}-b_{L}^{\frac{1}{v-1}}\right)\right]^{2}$.

Note 14. The Appendix provides proofs of the comparative static results.

Note 15. The sign of $\partial \beta / \partial v$ is that of $-1-\log [c]+\log [u v]-\log [v-1]$.

Note 16. Second order direct partial derivatives in $x_{i}$ are negative under the PF cost structure. Thus, the second order conditions to the principal's problem are met if we assume

$c_{a} c_{b}\left(v_{a}-1\right) x_{a}^{v_{a}-2} x_{b}^{v_{b}-2}>\left[\frac{v}{v-1} \theta_{a} \theta_{b}\left(u\left(a_{H}\right)-u\left(a_{L}\right)\right)\left(b_{L}^{-1}-b_{H}^{-1}\right)\right]^{2}$.

\section{Appendix}

\section{Proof of Lemma 1}

Consider first the case where the participation constraint is non-binding. For this case, we have that $\lambda=0$ and $\mu_{\alpha}=1$, so that $\alpha=0$, from (4).

The second case is the situation where the participation constraint is binding. Assume that the participation constraint is binding and that, to the contrary, $\alpha>0$. If $\alpha>0$, then from (4) $\mu_{\alpha}=0$ and $\lambda=1 / b>0$. Moreover, from (7), we have $\mu=(1-\beta) y a / c^{\prime \prime}$. However, (8), the condition for the optimal $\beta \geq 0$, implies

$$
\operatorname{yax}(\lambda b-1)+[(1-\beta)) y a b a y] / c^{\prime \prime}+\mu_{\beta}=0
$$

or that

$$
[(1-\beta) y a b a y] / c^{\prime \prime}+\mu_{\beta}=0
$$

Thus, under the assumption that the participation constraint is binding and $\alpha>0$, we obtain

$$
[(1-\beta) \text { yabay }] / c^{\prime \prime}=-\mu_{\beta} \leq 0
$$

This condition implies that $\beta \geq 1$, so that with $\alpha>0$, the principal's profit is negative. This cannot be optimal because doing nothing generates greater (zero) profit for the principal. Therefore, if the participation constraint is binding, it must be that $\alpha=0$.

Finally, note that A.1 implies that $c^{\prime}(x) x-c(x)>0$. If $u(a)=0$, then the incentive compatibility condition and the participation constraint tell us $c^{\prime}(x) x=\beta$ bay $x$ and

$$
\beta \text { bayx }-c(x)-0>0
$$

so that the participation constraint is non-binding.

\section{Proof of Lemma 2}

From (9), $x=(1-\beta) b a y x^{\prime}\left(\beta\right.$ bay), where $x^{\prime}=1 / c^{\prime \prime}$. From A.1, $x \geqq x^{\prime} \beta$ bay, so that $-x^{\prime} \beta b a y+(1-\beta) b a y x^{\prime} \geqq 0$. It follows that $(1-2 \beta)$ bayx $x^{\prime} \geqq 0$, so that $(1-2 \beta) \geqq 0$

\section{Proof of Proposition 1}

Compute $\partial\left(\pi_{B}^{a}-\pi_{B}^{a}\right) / \partial b=y G^{-1 \prime} a y-G^{-1^{\prime}}$ ay $\frac{c^{\prime \prime} G^{-1}+c^{\prime}}{b a y}+\frac{c^{\prime G^{-1}}}{b^{3}}$. Using $c^{\prime \prime} G^{-1}+c^{\prime}=b a y$, we have that $\partial\left(\pi_{B}^{a}-\right.$ $\left.\pi_{B}^{a}\right) / \partial b=G^{-1 \prime} a y^{2}(1-(a / b))+\left(c^{\prime} G^{-1}\right) /\left(b^{3}\right)$. The second term of the latter is positive while the first is non-negative, if $b \geqq a$. Using the same substitution, $\partial\left(\pi_{B}^{a}-\pi_{B}^{a}\right) / \partial y=G^{1}+G^{-1}$, $b a y^{2}(1-a / b)$. Again the first term is positive and the second is non-negative if $b \geqq a$. Likewise, $\partial\left(\pi_{B}^{a}-\pi_{B}^{a}\right) / \partial a=G^{-1 \prime} b y^{2}(1-a / b)$. This expression is increasing, constant or decreasing as $b \frac{\geq}{<} a$.

\section{Proof of Proposition 2}

Evaluate $\partial\left(\pi_{B}^{a}-\pi_{B}^{a}\right) / \partial b=S^{-1} u^{\prime}\left(c^{\prime \prime} S^{-1}+c^{\prime}\right) / b^{2}+c^{\prime} S^{-1} / b^{3}>0$ and $\partial\left(\pi_{B}^{a}-\pi_{B}^{a}\right) / \partial y=S^{-1}+S^{-1} u^{\prime} a>0$. By $\partial\left(\pi_{B}^{a}-\pi_{B}^{a}\right) / \partial a=2 S^{-1 \prime} u^{\prime} y+S^{-1 \prime} u^{\prime \prime}\left(a y-\frac{G}{b}\right)+S^{-1^{\prime \prime}}\left(u^{\prime}\right)^{2}\left(a y-\frac{G}{b}\right)-\left(\frac{S^{-1^{\prime}} u^{\prime}}{b}\right)\left(S^{-1} c^{\prime \prime \prime}+2 c^{\prime \prime}\right)$, it is clear that $u^{\prime}$ 
$=0$ implies that this derivative is zero. Moreover if $u^{\prime}$ is positive, then this expression cannot be signed without further information on the forms of $c$ and $u$.

\section{Proof of Proposition 3}

\section{See text.}

\section{Proof of Lemma 3}

In the PF model, the principal's FOC for the optimal $\beta$ includes

$$
(\text { ay })^{v /(v-1}\left(\frac{b}{c}\right)^{1 /(v-1)}\left[\left(\frac{1}{v-1}\right) \beta^{\frac{1}{v-1}}-\left(\frac{v}{v-1}\right) \beta^{\frac{1}{v-1}}\right]+\lambda(\text { bayx })+\mu_{\beta}=0
$$

Rewriting

$$
(a y)^{v /(v-1}\left(\frac{b}{c}\right)^{\frac{1}{v-1}}\left(\frac{1}{v-1}\right) \beta^{\frac{1}{v-1}}\left(\beta^{-1}-v\right)=-\lambda(\text { bayx })-\mu_{\beta} \leqq 0
$$

Thus, $\beta^{N} \geqq 1 / v$. If the participation constraint is non-binding, then $\lambda=\mu_{\beta}=0$ and $\beta^{N}=1 / v$.

\section{Comparative Statics of the PF Non-binding Case}

Let $H_{i j}, i, j=a, b$, denote the Jacobian of the system (23)-(24) in the choice variables $\left(x_{a}, x_{b}\right)$, where $H_{a b} \equiv$ $\partial^{2} E(\pi) / \partial x_{a} \partial x_{b}$. Also define $\Delta_{a} \equiv\left(a_{H}^{\frac{v}{v-1}}-a_{L}^{\frac{v}{v-1}}\right)$. We have that $H_{i i}=-c_{i}\left(v_{i}-1\right) x^{v_{i}-2}<0, i=a, b$, and $H_{a b}=k_{N} \Delta_{a} \Delta_{b}$. By assumption, $|H|>0$. Employing the usual techniques, we have

$$
\begin{gathered}
\frac{\partial x_{a}}{\partial \theta_{a}}=\frac{1}{|H|}\left[-k_{N} \Delta_{a} E\left(b^{-1}\right) H_{b b}+k_{N} x_{a} \theta_{b} \Delta_{a} \Delta_{b} H_{a b}\right]>0, \text { and } \\
\frac{\partial x_{b}}{\partial \theta_{a}}=\frac{1}{|H|}\left[-k_{N} \Delta_{a} E\left(b^{-1}\right) H_{b a}+k_{N} x_{a} \theta_{b} \Delta_{a} \Delta_{b} H_{a a}\right]>0
\end{gathered}
$$

Turning to variations in $\theta_{b}$, we have

$$
\begin{gathered}
\frac{\partial x_{a}}{\partial \theta_{b}}=\frac{1}{|H|}\left[-k_{N} \Delta_{a} E\left(b^{-1}\right) H_{b b}+k_{N} x_{a} \theta_{b} \Delta_{a} \Delta_{b} H_{a b}\right]>0, \text { and } \\
\frac{\partial x_{b}}{\partial \theta_{b}}=\frac{1}{|H|}\left[k_{N} \Delta_{a} E\left(b^{-1}\right) H_{b a}+k_{N} x_{a} \theta_{b} \Delta_{a} \Delta_{b} H_{a a}\right]>0
\end{gathered}
$$

Next, we present variations in $c$ and $c_{i}$. We have $\partial k_{N} / \partial c<0$,

$$
\begin{gathered}
\frac{\partial x_{a}}{\partial c}=\frac{1}{|H|}\left[-\frac{\partial k_{N}}{\partial c} \theta_{a} \Delta_{a} E\left(b^{\frac{1}{v-1}}\right) H_{b b}+\frac{\partial k_{N}}{\partial c} \Delta_{b} \theta_{b} E\left(a^{\frac{v}{v-1}}\right) H_{a b}\right]<0, \\
\frac{\partial x_{b}}{\partial c}=\frac{1}{|H|}\left[\frac{\partial k_{N}}{\partial c} \theta_{a} \Delta_{a} E\left(b^{\frac{1}{v-1}}\right) H_{b a}+\frac{\partial k_{N}}{\partial c} \Delta_{b} \theta_{b} E\left(a^{\frac{v}{v-1}}\right) H_{a a}\right]<0 \\
\frac{\partial x_{a}}{\partial c_{a}}=\frac{1}{|H|}\left(x_{a}^{v_{a}-1} H_{b b}\right)<0, \text { and } \frac{\partial x_{a}}{\partial c_{b}}=\frac{1}{|H|}\left(x_{b}^{v_{b}-1} H_{a a}\right)<0, \\
\frac{\partial x_{b}}{\partial c_{a}}=\frac{1}{|H|}\left(-x_{a}^{v_{a}-1} H_{b a}\right)<0, \text { and } \frac{\partial x_{b}}{\partial c_{b}}=\frac{1}{|H|}\left(x_{b}^{v_{b}-1} H_{a a}\right)<0
\end{gathered}
$$

Finally, consider variations in $\mathrm{y}$. We have $\frac{\partial k_{N}}{\partial y}>0$,

$$
\begin{gathered}
\frac{\partial x_{a}}{\partial y}=\frac{1}{|H|}\left[-\frac{\partial k_{N}}{\partial y} \theta_{a} \Delta_{a} E\left(b^{\frac{1}{v-1}}\right) H_{b b}+\frac{\partial k_{N}}{\partial y} \Delta_{b} \theta_{b} E\left(a^{\frac{v}{v-1}}\right) H_{a b}\right]>0, \text { and } \\
\frac{\partial x_{b}}{\partial y}=\frac{1}{|H|}\left[\frac{\partial k_{N}}{\partial y} \theta_{a} \Delta_{a} E\left(b^{\frac{1}{v-1}}\right) H_{b a}-\frac{\partial k_{N}}{\partial y} \Delta_{b} \theta_{b} E\left(a^{\frac{v}{v-1}}\right) H_{a a}\right]>0
\end{gathered}
$$


This completes the proof.

\section{Comparative Statics of the PF Binding Case}

Define $J$ as the Jacobian of the system (27)-(28) in the choice variables $\left(x_{a}, x_{b}\right), J_{a b} \equiv \frac{\partial^{2} E(\pi)}{\partial x_{a} \partial x_{b}}$. Define $\Lambda_{a} \equiv$ $a_{H}\left(u\left(a_{H}\right)\right)^{\frac{1}{v}}-a_{L}\left(u\left(a_{L}\right)\right)^{\frac{1}{v}}, \Lambda_{b}=\left(b_{H}^{-1}-b_{L}^{-1}\right)$, and $\Lambda_{u} \equiv u\left(a_{H}\right)-u\left(a_{L}\right) . \quad$ We $\quad$ have $\quad$ that $J_{i i}=-c_{i}\left(v_{i}-1\right) x_{i}^{v_{i}-1}, i=a, b$, and $J_{a b}=\frac{-v}{v-1} \theta_{a} \theta_{b} \Lambda_{b} \Lambda_{u} \geqq 0$, with equality if education is firm specific $\left(\Lambda_{u}=0\right)$.

We have assumed that $|J|>0$.

Consider the firm specific case where $\Lambda_{u}=0$ and $J_{a b}=0$. Considering variations in $\theta_{a}$ and $\theta_{b}$, we have

$$
\frac{\partial x_{a}}{\partial \theta_{a}}=\frac{1}{|J|}\left[-k_{B}\left(a_{H}-a_{L}\right) u^{\frac{1}{v}} J_{b b}\right]>0, \quad \frac{\partial x_{b}}{\partial \theta_{a}}=\frac{1}{|J|}\left[k_{B}\left(a_{H}-a_{L}\right) u^{\frac{1}{v}} J_{b a}\right]=0 .
$$

Next consider cost and cash flow variations. We have $\frac{\partial k_{B}}{\partial c}<0, \frac{\partial k_{B}}{\partial y}>0$. Differentiating,

$$
\begin{gathered}
\frac{\partial x_{a}}{\partial c}=\frac{1}{|J|}\left[-\frac{\partial k_{B}}{\partial c} \theta_{a} \Lambda_{a} J_{b b}\right]<0, \frac{\partial x_{b}}{\partial c}=\frac{1}{|J|}\left[\frac{\partial k_{B}}{\partial c} \theta_{a} \Lambda_{a} J_{b b}\right]=0, \\
\frac{\partial x_{a}}{\partial c_{a}}=\frac{1}{|J|}\left[x_{a}^{v_{a}-1} J_{b b}\right]<0, \frac{\partial x_{b}}{\partial c_{a}}=\frac{1}{|J|}\left[-x_{a}^{v_{a}-1} J_{b a}\right]=0, \\
\frac{\partial x_{a}}{\partial c_{b}}=\frac{1}{|J|}\left[-x_{b}^{v_{b}-1} J_{a b}\right]=0, \frac{\partial x_{b}}{\partial c_{b}}=\frac{1}{|J|}\left[x_{b}^{v_{b}-1} J_{a a}\right]<0, \\
\frac{\partial x_{a}}{\partial y}=\frac{1}{|J|}\left[-\frac{\partial k_{B}}{\partial y} \theta_{a} \Lambda_{a} J_{b b}\right]>0, \frac{\partial x_{b}}{\partial y}=\frac{1}{|J|}\left[\frac{\partial k_{B}}{\partial y} \theta_{a} \Lambda_{a} J_{b a}\right]=0 .
\end{gathered}
$$

Next we consider the non-firm specific case where $\Lambda_{u}>0$. For changes in $\theta_{a}$ we have

$$
\frac{\partial x_{a}}{\partial \theta_{a}}=\frac{1}{|J|}\left\{\left[-k_{B} \Lambda_{a}+\frac{v}{v-1} \Lambda_{u} E\left(b^{-1}\right)\right] J_{b b}-\frac{v}{v-1} x_{a} \Lambda_{u} \theta_{b} \Lambda_{b} J_{a b}\right\}
$$

The first term of this expression is mixed in sign and the second term is positive. From the FOC (27) we see that at an interior solution in $x_{a}$ we have that

$$
\left[k_{B} \Lambda_{a}-\frac{v}{v-1} \Lambda_{u} E\left(b^{-1}\right)\right]=\left(c_{a} x_{a}^{v_{a}-1}\right) / \theta_{a}>0 .
$$

It then follows that $\left[-k_{B} \Lambda_{a}+\frac{v}{v-1} \Lambda_{u} E\left(b^{-1}\right)\right] J_{b b}>0$ and $\frac{\partial x_{a}}{\partial \theta_{a}}>0$. Next,

$$
\frac{\partial x_{b}}{\partial \theta_{a}}=\frac{1}{|J|}\left\{\left[k_{B} \Lambda_{a}-\frac{v}{v-1} \Lambda_{u} E\left(b^{-1}\right)\right] J_{b a}+\frac{v}{v-1} x_{a} \Lambda_{u} x_{a} \Lambda_{u} \theta_{b} \Lambda_{b} J_{a a}\right\}>0 .
$$

The expressions for changes in $\theta_{b}$ are analogous. We have

$$
\begin{aligned}
& \frac{\partial x_{a}}{\partial \theta_{b}}=\frac{1}{|J|}\left\{\left[\frac{v}{v-1} \theta_{a} \Lambda_{u} x_{b} \Lambda_{b} J_{b b}-\frac{v}{v-1} E(u(a)) \Lambda_{b} J_{a b}\right] .\right. \\
& \frac{\partial x_{b}}{\partial \theta_{b}}=\frac{1}{|J|}\left[-\frac{v}{v-1} \theta_{a} \Lambda_{u} x_{b} \Lambda_{b} J_{a b}+\frac{v}{v-1} E(u(a)) \Lambda_{b} J_{a a}\right] .
\end{aligned}
$$

Finally, consider cost and cash flow variations. We have

$$
\frac{\partial x_{a}}{\partial c}=\frac{1}{|J|}\left[-\frac{\partial k_{B}}{\partial c} \theta_{a} \Lambda_{a} J_{b b}\right]<0, \frac{\partial x_{b}}{\partial c}=\frac{1}{|J|}\left[\frac{\partial k_{B}}{\partial c} \theta_{a} \Lambda_{a} J_{a b}\right]<0,
$$




$$
\begin{aligned}
& \frac{\partial x_{a}}{\partial c_{a}}=\frac{1}{|J|}\left[x_{a}^{v_{a}-1} J_{b b}\right]<0, \frac{\partial x_{b}}{\partial c_{a}}=\frac{1}{|J|}\left[-x_{a}^{v_{a}-1} J_{b a}\right]<0 \\
& \frac{\partial x_{a}}{\partial c_{b}}=\frac{1}{|J|}\left[-x_{b}^{v_{b}-1} J_{a b}\right]<0, \frac{\partial x_{b}}{\partial c_{b}}=\frac{1}{|J|}\left[-x_{b}^{v_{b}-1} J_{a a}\right]<0 .
\end{aligned}
$$

Finally $y$ produce

$$
\frac{\partial x_{a}}{\partial y}=\frac{1}{|J|}\left[-\frac{\partial k_{B}}{\partial y} \theta_{a} \Lambda_{a} J_{b b}\right]>0, \frac{\partial x_{b}}{\partial y}=\frac{1}{|J|}\left[\frac{\partial k_{B}}{\partial y} \theta_{a} \Lambda_{a} J_{b a}\right]>0
$$

\section{Proof of Proposition 4}

It is clear that $\partial\left(\partial E(\pi) / \partial x_{b}\right) \partial \Delta>0$. We have, from (31), that the sign of $\partial\left(\partial E(\pi) / \partial x_{b}\right) \partial \Delta$ is that of $\frac{y\left(\frac{v}{c(v-1)}\right)^{1 / v} \theta_{a} a_{H}(u+\Delta)^{\frac{1}{v}-1}}{v}-\frac{v}{v-1} \theta_{a} E\left(b^{-1}\right)$. We need to show

$$
\text { (*) } v E\left(b^{-1}\right)>\frac{y a_{H}}{c^{1 / v}\left(\frac{v(u+\Delta)}{v-1}\right)^{\frac{v-1}{v}}}
$$

We have established in Lemma 3 that $\beta\left(a_{H}, b_{H}\right)=\frac{c^{1 / v}\left(\frac{v(u+\Delta)}{v-1}\right)^{\frac{v-1}{v}}}{b_{H} a_{H} y}>\frac{1}{v}$, and (*) is equivalent to

$$
(* *) v E\left(b^{-1}\right)>\frac{1}{b_{H} \beta} \Leftrightarrow \beta>\frac{1}{E\left(b^{-1}\right) b_{H} v}
$$

Condition $(* *)$ is true by $\frac{1}{E\left(b^{-1}\right) b_{H}} \in(0,1)$.

The remainder of the proof can be shown by way of example. Take the case where the investment costs are quadratic, $\frac{c_{i} x_{i}^{v_{i}}}{v_{i}}=c_{i} x_{i}^{2} / 2$. Moreover, let $\mathrm{u}\left(a_{L}\right)=a_{L}$ and $\mathrm{u}\left(a_{H}\right)=a_{H}+\Delta$. We use these assumptions to obtain closed form solutions for $x_{i}$ and using these solutions we set

$$
y=12.8, \mathrm{c}=3.81, \theta_{b}=.41, \theta_{a}=.28, v=3.14, a_{L}=1.08, a_{H}=1.29, b_{L}=1.01, b_{H}=1.15, c_{a}=2.51, c_{b}=2.34
$$

Under these parametric specifications, $x_{a}$ is increasing in $\Delta$ over the range $\Delta \in(0,2)$, with profit positive and $x_{a}$ $\in(0, .5)$ for this range of $\Delta$. For the same parameter values, $x_{a}$ is decreasing in $\Delta \in(6,10)$, with profit positive and $x_{a} \in(0, .5)$. Next, set

$y=11.38, \mathrm{c}=3.81, \theta_{b}=.45, \theta_{a}=.3, v=3.21, a_{L}=1.002, a_{H}=1.22, b_{L}=1.05, b_{H}=1.8, c_{a}=2.45, c_{b}=2.49$

Under these values, for $\Delta \in(0,4), x_{b}$ is increasing in $\Delta$, with profit positive and $x_{b} \in(0,1)$. Moreover, for $\Delta \in$ $(6,10), x_{b}$ is decreasing in $\Delta$, with profit positive and $x_{b} \in(0,1)$.

\section{Proof of Proposition 5}

Our strategy will be to begin by setting $\gamma=b=1$. At this level, $\pi^{b}=\pi^{\gamma}$. Then we will show that the cutoff condition of the proposition holds. We have

$$
\begin{gathered}
\frac{\partial \pi^{N}}{\partial b}=\frac{S^{-1}(u(a)) c^{\prime}\left(S^{-1}(u(a))\right)}{b^{2}}, \frac{\partial \pi^{B c}}{\partial \gamma}=\frac{c^{\prime}\left(S^{-1}(\gamma u(a))\right) S^{-1}(\gamma u(a))}{\gamma^{2}} \\
+u(a) S^{-1^{\prime}}(\gamma u(a))\left(a y-\frac{c^{\prime}\left(S^{-1}(\gamma u(a))\right)}{\gamma}\right)-\frac{S^{-1}(\gamma u(a)) c^{\prime \prime}\left(S^{-1}(\gamma u(a))\right) S^{-1^{\prime}}(\gamma u(a)) u(a)}{\gamma^{2}}
\end{gathered}
$$

Using the fact that $S^{-1^{\prime}}=1 / c^{\prime \prime} x$, the latter can be written as

$$
\frac{\partial \pi^{B c}}{\partial \gamma}=\frac{c^{\prime}\left(S^{-1}(\gamma u(a))\right) S^{-1}(\gamma u(a))}{\gamma^{2}}+u(a) \frac{\gamma a y-c^{\prime}\left(s^{-1}(\gamma u(a))\right)}{\gamma c^{\prime \prime}\left(s^{-1}(\gamma u(a))\right) s^{-1}(\gamma u(a))}-\frac{1}{\gamma^{2}}
$$


The result $\frac{\partial \pi^{B c}}{\partial \gamma} \geq \frac{\partial \pi^{B}}{\partial b}$, for $\gamma=b$, holds if $\frac{\gamma a y-c^{\prime}\left(S^{-1}(\gamma u(a))\right)}{\gamma c^{\prime \prime}\left(S^{-1}(\gamma u(a))\right) S^{-1}(\gamma u(a))}-\frac{1}{\gamma^{2}}<0$. This condition can be rewritten as

$$
\mathrm{y} \geq \frac{1}{\gamma a}\left[c^{\prime}\left(S^{-1}(\gamma u(a))\right)+\frac{c^{\prime \prime}\left(S^{-1}(\gamma u(a))\right) s^{-1}(\gamma u(a))}{\gamma}\right]
$$

\section{Proof of Proposition 6}

Let $\mathrm{G}$ denote the Jacobian of the system (41)-(42) in the choice variables $\left(x_{a}, x_{\gamma}\right)$. We have $G_{i i}=c_{i}\left(v_{i}-1\right) x_{i}^{v_{i}-2}<$ $0, i=a, \gamma$, and $G_{a \gamma}=k_{B} \theta_{a} \theta_{\gamma} \Lambda_{a} \Lambda_{\gamma}>0$, where $\Lambda_{\gamma} \equiv \gamma_{H}^{\frac{1}{v}}-\gamma_{L}^{1 / v}$ and $\Lambda_{a}$ and $\Lambda_{\gamma}$ are defined as in the comparative statics of the binding PF case. We assume that $|G|>0$. First consider

$$
\frac{\partial x_{a}}{\partial \theta_{a}}=\frac{1}{|G|}\left\{\left[-k_{B} \Lambda_{a} E\left(\gamma^{\frac{1}{v}}\right)+\frac{v}{v-1} \Lambda_{u}\right] G_{\gamma \gamma}-\left[-k_{B} \theta_{\gamma} \Lambda_{\gamma} \Lambda_{a}\right] G_{a \gamma}\right\}
$$

The second term in $\{\cdot\}$ is positive whereas the first is mixed. However, from the first order condition (41)

$$
k_{B} \Lambda_{a} E\left(\gamma^{\frac{1}{v}}\right)-\frac{v}{v-1} \Lambda_{u}=\frac{c_{a} x_{a}^{v_{a}-1}}{\theta_{a}}>0
$$

Thus, $\frac{\partial x_{a}}{\partial \theta_{a}}>0$. Next,

$$
\frac{\partial x_{\gamma}}{\partial \theta_{a}}=\frac{1}{|G|}\left\{\left[-k_{B} \theta_{\gamma} \Lambda_{\gamma} x_{a} \Lambda_{a}\right] G_{a a}-\left[-k_{B} \Lambda_{a} E\left(\gamma^{\frac{1}{v}}\right)+\frac{v}{v-1} \Lambda_{u}\right] G_{a \gamma}\right\}>0
$$

Consider changes in $\theta_{\gamma}$ next. We have

$$
\begin{aligned}
& \frac{\partial x_{a}}{\partial \theta_{\gamma}}=\frac{1}{|G|}\left\{-k_{B} \theta_{a} \Lambda_{a} x_{\gamma} \Lambda_{\gamma}\right] G_{\gamma \gamma}-\left[-k_{B} \Lambda_{\gamma} E\left(a u(a)^{\frac{1}{v}}\right)\right] G_{a \gamma}>0 \\
& \frac{\partial x_{\gamma}}{\partial \theta_{\gamma}}=\frac{1}{|G|}\left\{\left[-k_{B} \Lambda_{\gamma} E\left(a u(a)^{\frac{1}{v}}\right)\right] G_{a a}-\left[-k_{B} \theta_{a} \Lambda_{a} x_{\gamma} \Lambda_{\gamma}\right] G_{\gamma a}>0\right.
\end{aligned}
$$

Effort cost parameter changes have the following effects

$$
\begin{gathered}
\frac{\partial x_{a}}{\partial c}=\frac{1}{|G|}\left\{\left[-\frac{\partial k_{B}}{\partial c} \theta_{a} \Lambda_{a} x_{\gamma} \Lambda_{\gamma}\right] G_{\gamma \gamma}-\left[-\frac{\partial k_{B}}{\partial c} \theta_{\gamma} \Lambda_{\gamma} E\left(a u(a)^{\frac{1}{v}}\right)\right] G_{\gamma a}\right\}<0 \\
\frac{\partial x_{\gamma}}{\partial c}=\frac{1}{|G|}\left\{\left[-\frac{\partial k_{B}}{\partial c} \theta_{\gamma} \Lambda_{\gamma} E\left(a u(a)^{\frac{1}{v}}\right)\right] G_{a a}-\left[-\frac{\partial k_{B}}{\partial c} \theta_{a} \Lambda_{a} E\left(\gamma^{\frac{1}{v}}\right)\right] G_{\gamma a}\right\}<0
\end{gathered}
$$

by $\frac{\partial k_{B}}{\partial c}<0$. Next, consider changes in training and motivation cost parameters.

$$
\begin{gathered}
\frac{\partial x_{a}}{\partial c_{a}}=\frac{1}{|G|} x_{a}^{v_{a-1}} G_{\gamma \gamma}<0 \\
\frac{\partial x_{\gamma}}{\partial c_{a}}=-\frac{1}{|G|} x_{a}^{v_{a-1}} G_{\gamma a}<0 \\
\frac{\partial x_{\gamma}}{\partial c_{\gamma}}=\frac{1}{|G|} x_{\gamma}^{v_{\gamma-1} G_{a a}<0}
\end{gathered}
$$

Finally changes in $y$ produce changes analogous to those of changes in $c$. We have 


$$
\begin{gathered}
\frac{\partial x_{a}}{\partial y}=\frac{1}{|G|}\left\{\left[-\frac{\partial k_{B}}{\partial y} \theta_{a} \Lambda_{a} E\left(\gamma^{\frac{1}{v}}\right)\right] G_{\gamma \gamma}-\left[-\frac{\partial k_{B}}{\partial y} \theta_{\gamma} \Lambda_{\gamma} E\left(a u(a)^{\frac{1}{v}}\right)\right] G_{\gamma a}\right\}>0 \\
\frac{\partial x_{\gamma}}{\partial y}=\frac{1}{|G|}\left\{\left[-\frac{\partial k_{B}}{\partial y} \theta_{\gamma} \Lambda_{\gamma} E\left(a u(a)^{\frac{1}{v}}\right)\right] G_{a a}-\left[-\frac{\partial k_{B}}{\partial y} \theta_{a} \Lambda_{a} E\left(\gamma^{\frac{1}{v}}\right)\right] G_{\gamma a}\right\}>0
\end{gathered}
$$

by $\frac{\partial k_{B}}{\partial y}>0$.

We turn next to a replication of the results of Proposition 4 for the case where effort reduces effort cost. The FOC for choice of investment levels read as follows.

$$
\begin{aligned}
& \frac{\partial E(\pi)}{\partial x_{a}}=k_{B} \theta_{a}\left(a_{H}(u+\Delta)^{\frac{1}{v}}-a_{L} u^{\frac{1}{v}}\right) E\left(\gamma^{\frac{1}{v}}\right)-\frac{v}{v-1} \theta_{a} \Delta-c_{a} x_{a}^{v_{a}-1}=0 \\
& \frac{\partial E(\pi)}{\partial x_{\gamma}}=k_{B} \theta_{\gamma}\left(\gamma_{H}^{\frac{1}{v}}-\gamma_{L}^{\frac{1}{v}}\right)\left[\theta_{a} x_{a} a_{H}(u+\Delta)^{\frac{1}{v}}+\left(1-\theta_{a} x_{a}\right) a_{L} u^{\frac{1}{v}}\right]-c_{a} x_{a}^{v_{a}-1}=0
\end{aligned}
$$

Again $\partial\left[\partial E(\pi) / \partial x_{\gamma}\right] / \partial \Delta=k_{B} \theta_{\gamma}\left(\gamma_{H}^{\frac{1}{v}}-\gamma_{L}^{\frac{1}{v}}\right)\left[\frac{1}{v} \theta_{a} x_{a} a_{H}(u+\Delta)^{\frac{1}{v}-1}\right]>0$. Using the strategy the proof of Proposition 4 ,

$$
\left[\partial E(\pi) / \partial x_{a}\right] / \partial \Delta=k_{B} \theta_{a}\left[\left(\frac{1}{v}\right) a_{H}(u+\Delta)^{\frac{1-v}{v}} E\left(\gamma^{\frac{1}{v}}\right)\right]-\frac{\theta_{a} v}{v-1}
$$

This is negative if $\left(k_{B}=y\left(\frac{v}{c(v-1)}\right)^{\frac{1}{v}}\right)$

$$
\left.\frac{v}{E\left(\gamma^{\frac{1}{v}}\right)}>\frac{v-1}{v} y\left(\frac{v}{c(v-1)}\right)^{\frac{1}{v}}\right) a_{H}(u+\Delta)^{\frac{1-v}{v}}
$$

Rewriting,

$$
\frac{v}{E\left(\gamma^{\frac{1}{v}}\right)}>\frac{y a_{H}}{c^{1 / v}\left(\frac{v(u+\Delta)}{v-1}\right)^{v-1 / v}}=\frac{1}{\beta\left(a_{H}, \gamma_{H}\right)}
$$

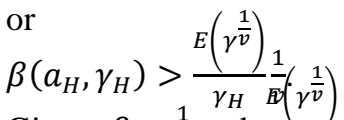

Given $\beta>\frac{1}{v}$ and $\frac{\gamma_{H}}{\gamma_{H}} \in(0,1)$, by $v>2$ and $\gamma_{-}\{i\}>1$, the result holds.

Finally consider the quadratic example from Proposition 4. Let

$$
\frac{c_{i} x_{i}^{v_{i}}}{v_{i}}=\frac{c_{i} x_{i}^{2}}{2}, i=a, \gamma, \text { and } u\left(a_{L}\right)=a_{L}, u\left(a_{H}\right)=a_{L}+\Delta
$$

We found $x_{i}$ to determine that changes in $\Delta$ can lead to both increases and decreases in $x_{i}$. The closed form solutions were computed using Mathematica and are omitted because of their complexity. Let

$y=12.8, c=3.81, \theta_{\gamma}=.41, \theta_{a}=.28, v=3.14, a_{L}=1.08, a_{H}=1.29, \gamma_{H}=1.15, \gamma_{L}=1.01, c_{a}=2.51$, and $c_{\gamma}=$ 2.34 .

Investment in $x_{a}$ is increasing in the interval $\Delta \in(0,3)$ and decreasing in the interval $\Delta \in(4,10)$. Moreover, if $y=11.8, c=2.91, \theta_{\gamma}=.83, \theta_{a}=.64, v=3.38, a_{L}=1.1, a_{H}=1.23, \gamma_{H}=1.15, \gamma_{L}=1.06, c_{a}=2.43$, and $c_{\gamma}=$ 2.33,

Then investment $x_{\gamma}$ is increasing in the interval $\Delta \in(0,5)$ and decreasing in the interval $\Delta \in(5,10)$. This completes the proof. 